\title{
The Application of Evolutionary Algorithms in Multi-Objective Design and Optimization of Air Cooled Heatsinks
}

Younis Osama Abdelsalam

Trinity College, University of Dublin, abdelsay@tcd.ie

Sajad Alimohammadi

Technological University Dublin, sajad.alimohammadi@tudublin.ie

Tim Persoons

Trinity College Dublin, Department of Mechanical and Manufacturing Engineering, Dublin, Ireland

Follow this and additional works at: https://arrow.tudublin.ie/engschmanart

Part of the Energy Systems Commons, and the Heat Transfer, Combustion Commons

\section{Recommended Citation}

Abdeisalam, Y., Alimohammadi, S., \& Persoons, T. (2020). The application of evolutionary algorithms in multi-objective design and optimization of air cooled heatsinks. Jurnal of Thermal Science and Engineering Applications, 12(2): 021003 . doi:10.1115/1.4044165

This Article is brought to you for free and open access by the School of Manufacturing and Design Engineering at ARROW@TU Dublin. It has been accepted for inclusion in Articles by an authorized administrator of ARROW@TU Dublin. For more information, please contact arrow.admin@tudublin.ie, aisling.coyne@tudublin.ie, gerard.connolly@tudublin.ie.

Funder: Science Foundation Ireland (SFI); Irish Research Council (IRC)

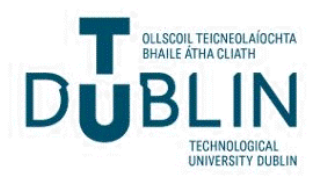




\title{
The Application of Evolutionary Algorithms in Multi-Objective Design and Optimisation of Air Cooled Heatsinks
}

\author{
Younis Osama Abdelsalam ${ }^{1}$, Sajad Alimohammadi ${ }^{2,3}$, Tim Persoons ${ }^{4}$ \\ ${ }^{1}$ Department of Mechanical \& Manufacturing Engineering, University of Dublin, Trinity College, Dublin, \\ Ireland (abdelsay@tcd.ie) \\ ${ }^{2}$ School of Mechanical \& Design Engineering, Technological University Dublin, City Campus, Dublin, Ireland \\ (sajad.alimohammadi@dit.ie) \\ ${ }^{3}$ Department of Mechanical \& Manufacturing Engineering, University of Dublin, Trinity College, Dublin, \\ Ireland (alimohas@tcd.ie) \\ ${ }^{4}$ Department of Mechanical \& Manufacturing Engineering, University of Dublin, Trinity College, Dublin, \\ Ireland (tim.persoons@tcd.ie)
}

\section{Abstract}

Genetic Algorithms (GA) are considered to be one of the main types of Evolutionary Algorithms (EA) and are being increasingly used in various engineering design applications. To a large extent, plate-fin heatsinks are used in the thermal management of compact electronic equipment and data centres. The shape optimisation of the heatsinks is not rigorously investigated during the design process of high power electronics. Any improvements in the effectiveness of the heatsinks impacts the energy consumed by large scale ICT facilities including data centres and telecommunication systems and promotes a more sustainable use of raw materials.

This paper investigates the optimisation of plate-fin heatsinks by modifying the fin layout in a forced cross-flow using a multi-objective genetic algorithm (MOGA) combined with CFD simulations. The main objective is to improve the heat dissipation rate by modifying geometric parameters, i.e., the number, arrangement, and orientation of fins. For a generic heatsink test case, the optimised performance is examined in terms of thermal resistance, turbulence intensity, pumping power, coefficient of performance, and Chilton-Colburn j-factors.

Among all of the cases investigated, the input parameter optimisation configurations which coupled and rotated fins in groups of ten, proved to be the most successful. For one case, an $18 \%$ increase in the effectiveness of heat dissipation is reported. However, when weight reduction was considered by dividing by the unit mass, the designs in one of the investigated families which removes a number of fins from the heatsink outperformed the rest, achieving improvements of $65 \%$ over the baseline.

Keywords: Shape optimisation, Convective heat transfer, Electronics cooling, Coefficient of performance, Genetic algorithm, MOGA, Computational fluid dynamics 


\section{LIST OF FIGURES}

Figure 1: Schematic diagram of (a) plate-fin heatsink, (b) two-dimensional channel $(\mathrm{b}<<\mathrm{H})$............ 8

Figure 2: Heatsink dimensions: (a) Baseline, (b) Double Cut ............................................................ 11

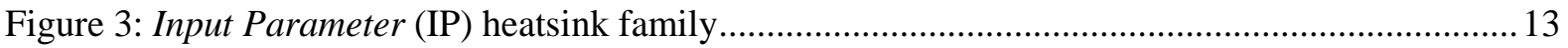

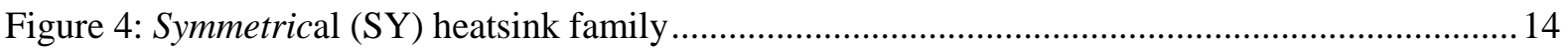

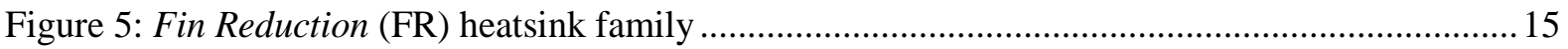

Figure 6: a) The mesh (Double Cut design example), b) Mesh comparison: Design 1, 3, and 5 ......... 16

Figure 7: Evaluation cycle for the optimisation loop..................................................................... 18

Figure 8: Heat transfer progression through the generations (for IP 10) …........................................ 18

Figure 9: Genetic algorithm progression through the generations for design IP 10 ............................. 19

Figure 10: Overview of heat transfer rate for each optimized geometric variant, (a) Normal, (b) Per

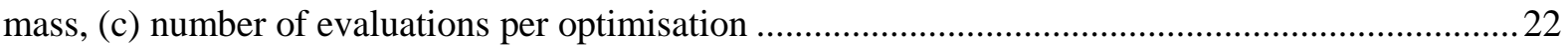

Figure 11: Thermal resistance for (a) Input Parameter (IP), (b) Symmetrical (SY), (c) Fin Reduction

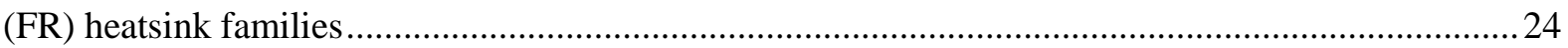

Figure 12: Thermal resistance per mass for the Fin Reduction family ..............................................25

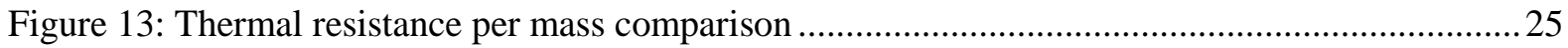

Figure 14: (a) Turbulence intensity, (b) Pumping power, (c) COP as a function of heat transfer rate. 27

Figure 15: Coefficient of performance as a function of heat transfer rate per unit mass .......................2

Figure 16: Flow velocity (left) and temperature (right) fields for heatsink designs (a) Baseline, (b)

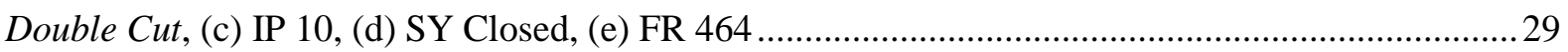

Figure 17: Correlation between heat j-factor and friction j-factor ..................................................... 30

Figure 18: Correlation between heat $\mathrm{j}$-factor per unit mass and friction $\mathrm{j}$-factor per unit mass ............ 31 


\section{LIST OF TABLES}

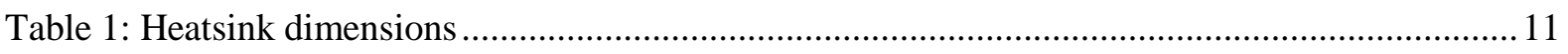

Table 2: Fin angle rotation ranges for optimisation (IP = Input Parameter, $\mathrm{SY}=$ Symmetrical, $\mathrm{FR}=$ Fin Reduction)

Table 3: Example mesh properties of Double Cut design (mesh independent results). 17 


\begin{tabular}{|c|c|c|c|}
\hline \multicolumn{4}{|c|}{ Nomenclature } \\
\hline$A$ & Surface area $\left[\mathrm{m}^{2}\right]$ & $\operatorname{Pr}$ & Prandtl number, $C_{p} \mu / k$ \\
\hline$b$ & Spacing between heatsink fins $[\mathrm{m}]$ & $p$ & Perimeter $[\mathrm{m}]$ \\
\hline$d$ & Spacing between heatsink shorter fins [mm] & $Q$ & Volumetric flow rate $\left[\mathrm{m}^{3} / \mathrm{s}\right]$ \\
\hline$C_{p}$ & Specific heat $[\mathrm{J} /(\mathrm{kg} . \mathrm{K})]$ & $q$ & Heat transfer rate $[\mathrm{W}]$ \\
\hline$C O P$ & Coefficient of performance & $R$ & Thermal resistance $[\mathrm{K} / \mathrm{W}]$ \\
\hline$D_{h}$ & Hydraulic diameter $[\mathrm{m}]$ & $\operatorname{Re}$ & Reynolds number, $\rho U D_{h} / \mu$ \\
\hline$f$ & Fanning friction factor & $S$ & Distance between rows [m] \\
\hline$H$ & Height of heatsink $[\mathrm{m}]$ & $T_{a}$ & Ambient fluid temperature $[\mathrm{K}]$ \\
\hline$H_{f}$ & Height of fin $[\mathrm{m}]$ & $T_{f}$ & Film temperature $[\mathrm{K}]$ \\
\hline$h$ & Convective heat transfer coefficient $\left[\mathrm{W} / \mathrm{m}^{2} \mathrm{~K}\right]$ & $T_{s}$ & Surface temperature $[\mathrm{K}]$ \\
\hline$I$ & Turbulence Intensity & $t$ & Fin thickness $[\mathrm{m}]$ \\
\hline$j_{f}$ & Chilton-Colburn friction $\mathrm{j}$-factor & $U$ & Uniform fluid velocity $[\mathrm{m} / \mathrm{s}]$ \\
\hline$j_{H}$ & Chilton-Colburn heat transfer j-factor & $U_{a v}$ & Average fluid velocity $[\mathrm{m} / \mathrm{s}]$ \\
\hline & & $g$ & \\
\hline$k$ & Thermal conductivity $[\mathrm{W} /(\mathrm{m} . \mathrm{K})]$ & $W$ & Width of heatsink plate [m] \\
\hline$K_{t}$ & Turbulence kinetic energy $\left[\mathrm{m}^{2} / \mathrm{s}^{2}\right]$ & & \\
\hline$L$ & Length of fin $[\mathrm{m}]$ & Gre & k Symbols \\
\hline$l$ & Length of short fin $[\mathrm{m}]$ & $\Delta T$ & Temperature difference $[\mathrm{K}]$ \\
\hline$g$ & Gap between two halves of heatsink [m] & $\Delta P$ & Pressure difference $[\mathrm{Pa}]$ \\
\hline$m$ & Fin efficiency parameter & $\eta$ & Fin efficiency \\
\hline$N$ & Number of fins & $\mu$ & Dynamic viscosity $\left[\mathrm{Ns} / \mathrm{m}^{2}\right]$ \\
\hline $\mathrm{Nu}$ & Nusselt number & $\rho$ & Density $\left[\mathrm{kg} / \mathrm{m}^{3}\right]$ \\
\hline$P_{p}$ & Pumping power [W] & $\eta_{p}$ & Pump efficiency \\
\hline
\end{tabular}

\section{Introduction}

Plate-fin heatsinks are commonly used as devices that enhance the heat dissipation by dispersing heat from one source to another. They act as thermal conductors, transferring the heat from electronic devices into fins, which provide larger surface areas, effectively cooling both the heatsink and the electronic device. In a world with an increasing demand for cloud computing, information communication technology (ICT) infrastructures and data centres are consuming larger quantities of energy to maintain the servers at ideal operating temperatures. This ensures the long-term reliability and performance of electronic components. Over the course of the last half century, the performance of electronic devices steadily grew. Large scale ICT equipment consume a substantial sum of the annual global electrical energy (1.3\% in 2010). Almost 30\% of the energy consumption in the data centre is being used on the thermal management. From 2014 to 2017, a 15\% growth in data centre business was reported [1]-[2]. 
While the liquid-cooled CPUs in hybrid-cooled servers are growing fast, the majority of electronics rely on using air as the cooling medium. Air is the most accessible coolant, and the methods based on it are simple and robust. Particularly with respect to its safe operations in hostile environments (contaminated air, vibrations, noise, humidity) [3]. For many years the optimisation of heatsinks was conducted based on analytical models or simplified numerical models. More recently, with the availability of high computational power, common engineering tool such as complex CFD simulations can be applied for thermal analyses and design optimisation of heatsinks.

Electronic devices are continuously miniaturised, yet rudimentary cooling methods are still being applied to the now modern electronics. As the devices take up new and compact shapes, less surface area and volume is available to dissipate the heat surging from the devices and this is becoming a pressing issue. As a result, any improvements in the efficiency of the heatsinks will have a drastic impact on the energy consumed by the ICT centres on a global level, as well as reducing their carbon footprint.

\section{I.1 Using Numerical Shape Optimisation for Heatsink Design}

The demand for lower thermal resistance heatsinks has motivated the investigation of an abundant variety of methods for the design enhancement, e.g., using the volume averaging theory [4], the entropy minimisation [5], and the most popular, the plate-fin geometry manipulation [3], [6]-[12].

The choice of an optimal heatsink depends on a number of geometric parameters such as the fin height, length, thickness, profile, material, and so on. Due to the time-consuming nature of tackling all of these parameters at once, most experiments are conducted by only varying one parameter at a time. In most cases, any improvement of the heatsink thermal performance has to be made with respect to practical constraints, like the available pressure drop, external dimensions, mass, volume or cost. However, due to the evolution of CFD software, multiple objectives can be optimised at once using a genetic algorithm (GA). The Genetic Algorithm as a method of optimisation is inspired and based on the natural selection process of genetic mutation in the biological evolution. The term genetic is to resemble the idea of the whole method being based on the biological evolution process.

Karathanassis et al. [14] investigated the design optimisation of a micro heatsink using a multi-objective genetic algorithm (MOGA). The thermal resistance and the cooling fluid pressure drop were considered as the optimisation objectives. The optimisation procedure resulted in the optimal trade-off between the two evaluation criteria, each of mutually conflicting nature. The vast majority of optimal solutions discovered favoured channels with a small hydraulic diameter resulting in a configuration with low thermal resistance and high pressure drop [14].

Horiuchi et al. [15] also considered a multi-objective optimisation but for water-cooled pin-fin heatsinks. The heat transfer rate and pressure drop were used as the objectives of optimisation. Four 
parameters of the pin-fin geometry, namely, height, diameter, longitudinal pitch, and transverse pitch, were also used as the design variables along with two constraints; the clearance between the tip of the pins and the flow channel and the minimum gap considering cost-effectiveness and manufacturability. The trade-off curves between the pressure drop and the heat transfer rate were calculated using a genetic algorithm which provided them with a geometry which was further improved by increasing the constraints for the clearance between the tip of the pins and the flow channel [15].

Chen et al. [16] looked at a new approach for optimising the heatsink design to use over the common approach of minimisation of the entropy. They discovered that a lower entropy generation rate often corresponds to a larger heatsink design. To balance the design of heatsinks for heat dissipation, they considered the simultaneous minimisation of entropy and the material cost of the heatsink using a multiobjective, direction based genetic algorithm. Their results conclude that using this approach, a balanced design for heatsinks can be achieved for both the benefits of lightweight and excellent heat dissipation [16].

Younes and Potiron [17] investigated the possibility of using the genetic algorithm to optimise the shapes of bodies subjected to thermal loading. Their investigations concluded that the GA can be a reliable tool that leads to practical results in the shape optimisation problems. Although they examined the optimisation of structural beams, their methods proved to be successful under two-dimensional structures, obtaining results closely matching the analytical calculations. The accuracy they have achieved using what could be considered primitive models emphasises the validity and the potential of genetic algorithm for shape optimisation [17].

The lack of extensive literature on heatsink optimisation using genetic algorithms remains opens a new avenue for design explorations as the works of Karathanassis et al. [14], Horiuchi et al. [15], Chen et al. [16] and Younes and Potiron [17] demonstrated. The genetic algorithms are shown as reliable for producing accurate results. These findings in combination with the advantageous heat transfer performance of plate fins arranged in a co-angular pattern and zigzag pattern (e.g., Didarul et al. [7]), gave inspiration for a new design approach to optimise plate-fin heatsinks in this paper. The first stage of this research has been published in the proceedings of the Therminic 2017 workshop [18]. In the current paper, an extended set of results and discussions are included as a follow-up. The fluid flow features are presented in more detail to assess the linkages between the momentum boundary layer and the thermal boundary layer, and the overall effect on the heatsink performance. More in-depth details regarding the development of the computational mesh and both CFD and GA models are also incorporated. In addition, building on the work by Sparrow et al. [9], the effects of removing a number of shorter fins will also be examined here. Other works by Tye-Gingras and Gosselin [19] combined the thermal resistance minimization with the use of genetic algorithms and Cavazzuti and Corticelli [20] introduced the enhanced surface optimization using multi-objective genetic algorithms. 
This paper examines new fin arrangements and orientations that have been generated using genetic algorithms, providing an extensive set of results. The paper also analyses their apparent effects on the performance of heatsinks and how they could be modified to further increase the heat dissipation efficiency.

\section{Theoretical Background}

\section{II.1 Plate-fin Theory}

Teertstra et al. [21] developed a model that predicts the average heat transfer rate for forced convection air cooling plate-fin heatsinks. Using a composite solution based on the limiting cases of fullydeveloped and developing flow between isothermal parallel plates, the average Nusselt number can be calculated as a function of the heatsink geometry and the fluid velocity [18].

The plate-fin heatsink shown in Fig. 1 (a) consists of a parallel, uniform array of thin, conductive plates of length $\mathrm{L}$, height $\mathrm{H}$ and thickness $\mathrm{t}$, mounted on a baseplate of dimensions $\mathrm{L} \times \mathrm{W}$ [21].

\section{II.2 Problem Development}

The baseplate is assumed relatively thick and composed of a high conductive material, such that the spreading resistance effects can be neglected and thus the baseplate can be treated as an isothermal surface. The lower surface and edges of the baseplate are assumed to be adiabatic. The heatsink is modelled as $\mathrm{N}-1$ parallel 2D plate channels, i.e., with each channel defined as shown in Fig. 1 (b) with the uniform inlet velocity $\mathrm{U}$ and the ambient fluid temperature $\mathrm{T}_{\mathrm{a}}$. All air properties are calculated at the film temperature: $T_{f}=\left(T_{S}+T_{a}\right) / 2$ [18].

(a)

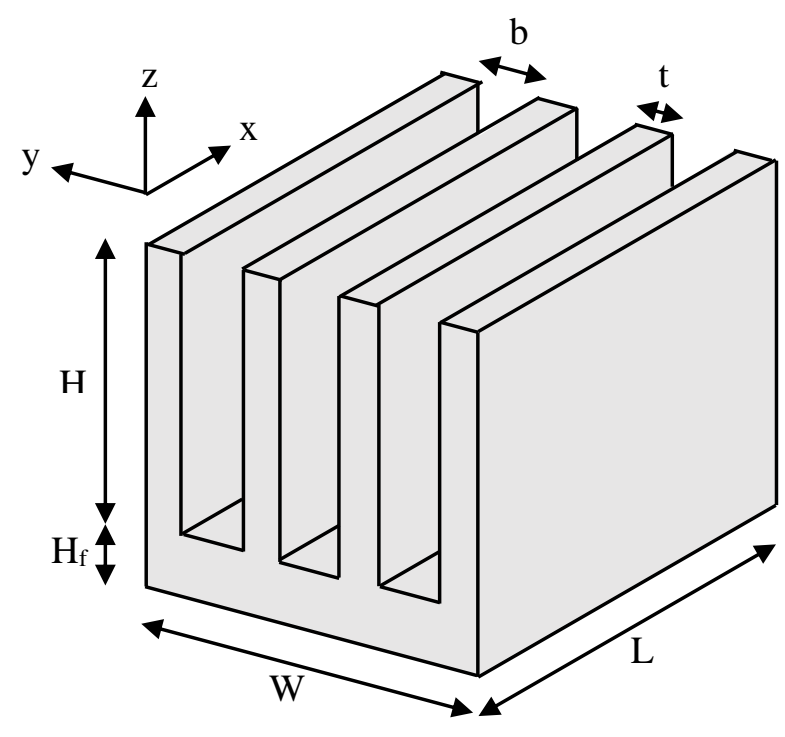


(b)

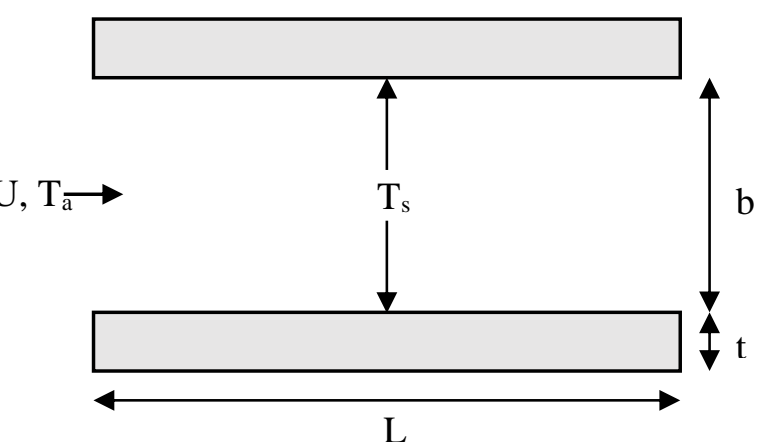

Figure 1: Schematic diagram of (a) plate-fin heatsink, (b) two-dimensional channel (b $<<\mathrm{H})$

\section{II.3 Determining the Heat Transfer Coefficient}

To determine the heat transfer coefficient acting upon the fins, Teertstra et al. [21] developed a heat transfer correlated model based on numerical simulations relating the Nusselt number, $\mathrm{Nu}$, to Reynolds number, Re, and Prandtl number, Pr. Reynolds number uses the hydraulic diameter $\left(D_{h}\right)$ of the channel as the characteristic length [18].

$$
\begin{gathered}
N u_{b}=\left[\frac{1}{\left(\frac{R e P r}{2}\right)^{n}}+\frac{1}{\left(0.664 \sqrt{\operatorname{Re} P r^{1 / 3}} \sqrt{1+\frac{3.65}{\operatorname{Re}}}\right)^{n}}\right]^{-1 / n} \\
\operatorname{Re}=\frac{\rho U D_{h}}{\mu}
\end{gathered}
$$

When $\mathrm{n}=3$, the root mean square (RMS) percent difference between the model and the numerical data is $2.1 \%$ [21]. Where

$$
D_{h}=\frac{2 H_{f} b}{H_{f}+b}
$$

and, $b$ is the width of the channel and $\mathrm{H}_{\mathrm{f}}$ is the height of the fin. The width of the channel refers to the individual channels between the fins, not the heatsink base width as illustrated in Fig. 1 (a).

The average heat transfer coefficient, $\mathrm{h}$, can be calculated using $\mathrm{Nu}_{\mathrm{b}} \frac{\mathrm{k}_{\mathrm{f}}}{\mathrm{D}_{\mathrm{h}}}[18]$.

\section{II.4 Fin Effects}

The goal in high aspect ratio heatsink configurations is to maximise the available fin surface area. As the fins become taller and thinner, the temperature difference between the fins and the baseplate increases due to the increased conductive resistance, reducing the heatsink performance [18]. This effect is more pronounced for forced convection, where strong convection on the fins tends to remove the heat more quickly than it can be replaced through conduction from the baseplate [21]. 
Assuming adiabatic conditions at the fin top, the efficiency can be determined as follows:

$$
\eta=\frac{\tanh \left(m H_{f}\right)}{m H_{f}}
$$

where $m$ is defined as $\sqrt{\mathrm{hp} / \mathrm{kA}}$.

The perimeter $p=2 t+2 L$ and the cross-sectional area $A_{c}=t_{L}$, where $k$ is the thermal conductivity of the fin material, $\mathrm{t}$ is the thickness and $\mathrm{L}$ is the length of the fin [21].

\section{II.5 Thermal Resistance}

Thermal resistance is defined as the difference between the base temperature of the heatsink at the outlet and the fluid bulk mean temperature at the inlet per unit heat transfer rate. $\mathrm{R}=\frac{\Delta \mathrm{T}}{\mathrm{q}}$ is the thermal resistance, $\Delta \mathrm{T}$ is the temperature difference between the heatsink and bulk fluid, and $\mathrm{q}$ is the heat transfer rate.

The thermal resistance can be decomposed into the convective resistance, which is related to the heat transfer from the fins to the coolant, $R_{\text {conv }}=1 / \mathrm{hA}$, and the conductive resistance of the heat as it travels from the baseplate to the fins, $\mathrm{R}_{\text {cond }}=\mathrm{L} / \mathrm{kA},[4]$.

Factoring in the fin efficiencies and the area of the baseplate exposed to the fluid, the convective thermal resistance becomes:

$$
\begin{gathered}
A_{\text {fin }}=2 N H_{f} L \\
A_{\text {base }}=(N-1) b L \\
R_{\text {conv }}=\frac{1}{h\left(A_{\text {base }}+\eta A_{\text {fin }}\right)}
\end{gathered}
$$

where $\mathrm{N}$ is the number of fins and $\eta$ is the efficiency of each fin.

The total resistance is the summation of the above.

$$
R_{\text {tot }}=R_{\text {conv }}+R_{\text {cond }}
$$

\section{II.6 Chilton-Colburn J-Factor}

The empirical j-factor analogy proposed by Chilton and Colburn is a dimensionless number which groups certain terms that relates the heat, momentum, and mass transfer [18]. The $\mathrm{j}$-factor provides an excellent correlation of the data for any of the two transport processes near flat surfaces and proved to be the most accurate compared to other analogies [22]. The relationship between heat and friction is as follows:

$$
j_{H}=\frac{N u}{R e P r^{1 / 3}}
$$




$$
j_{f}=\frac{f}{2}
$$

where $\mathrm{j}_{\mathrm{H}}$ is the $\mathrm{j}$-factor for heat transfer, $\mathrm{j}_{\mathrm{f}}$ is the $\mathrm{j}$-factor for friction, relating to the pumping power required, and $\mathrm{f}$ is the Darcy friction factor used to characterise the dimensionless pressure drop. By rearranging the equation for Fanning friction factor and the $\mathrm{j}$-factor, the pressure drop, $\Delta \mathrm{P}$, across the heatsink can be determined [18].

$$
f=\frac{\Delta P}{\frac{L}{D_{h}} \frac{\rho u^{2}}{2}}
$$

\section{II.7 Pumping Power}

The pumping power is the rate of increase in the mechanical energy of a fluid as it passes through a pumping mechanism. Using the conservation of mechanical energy, the difference in the energy in the fluid before and after it passes the pumping mechanism can be calculated and thus the pumping power, $\mathrm{P}_{\mathrm{p}}[18]$.

$$
P_{p}=\frac{\Delta P Q}{\eta_{p}}
$$

where $\Delta \mathrm{P}$ is the change in pressure between the inlet and outlet, $\mathrm{Q}$ is the volumetric flow rate of the fluid and $\eta_{p}$ is the pump efficiency. For simplicity, the pumping efficiency is assumed to be 1 [18].

The effectiveness of the heatsinks can also be quantified by the coefficient of performance.

$$
C O P=\frac{\mathrm{q}}{P_{p}}
$$

\section{II.8 Turbulence Intensity}

The turbulence intensity, I, is defined as the ratio of the magnitude of the root-mean-square of the velocity fluctuations, $U$ ', to the mean flow velocity, $U_{\text {avg }}$ [25]. The turbulence intensity can be determined from the turbulent kinetic energy $\mathrm{k}_{\mathrm{t}}$ (in a two-dimensional CFD simulation) as follows:

$$
I=\frac{\sqrt{\frac{2}{3}} k_{t}}{U_{\text {avg }}}
$$

\section{Methodology}

The optimisation of plate-fin heatsinks using a multi-objective genetic algorithm (MOGA) in combination with CFD simulations is implemented in ANSYS Fluent. The main goals are to improve the rate at which heat is dissipated from heatsinks. This study only considers plate-fin heatsinks in a forced crossflow configuration [18]. 
A CFD model is first developed to study the heat transfer from a Baseline heatsink, Fig. 2 (a), the dimensions of which are outlined in Table 1. The Baseline design is inspired by Malico heatsink model number H21-06 [29]. The heatsink has $6.3 \mathrm{~mm}$ in height, with a baseplate thickness of $1.7 \mathrm{~mm}$ [18].

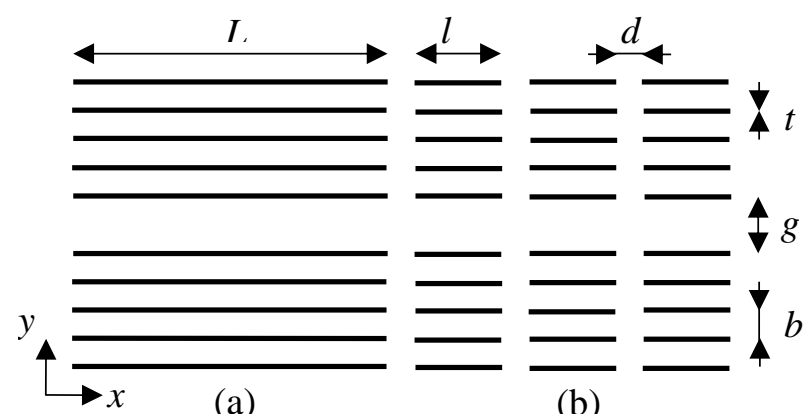

Figure 2: Heatsink dimensions: (a) Baseline, (b) Double Cut

Table 1: Heatsink dimensions

\begin{tabular}{lcccccc}
\hline Dimension & $L$ & $l$ & $t$ & $g$ & $b$ & $d$ \\
\hline Value $(\mathrm{mm})$ & 21.5 & 6.6 & 0.6 & 2.4 & 1.6 & 1.4
\end{tabular}

The results are compared to heatsink characteristics estimated analytically based on the parallel plate theory as laid out by Teertstra et al. [21].

A MOGA loop is then combined with CFD simulations to modify heatsink geometric parameters, i.e., rotation and removal of fins, while monitoring its heat transfer performance. For all investigated heatsinks configurations, the optimised model performance is examined in terms of the thermal resistance, turbulence intensity, pumping power, coefficient of performance and j-factors.

\section{III.1 Operating Conditions}

Each of the four investigated heatsink families was carried out under the same operating conditions. The fluid, air, was set to a temperature of $20^{\circ} \mathrm{C}$, a Reynolds number of 267 , and the inlet velocity with a turbulence intensity of 5\%. The Reynolds number of 267 was only used to obtain the optimum fin angle configuration of all the designs simulated. The range of Reynolds number used in the results section was used to determine the performance of the fin angles the GA generated under various flow speeds in transient conditions.

The heatsink fins were set to an isothermal temperature of $70^{\circ} \mathrm{C}$. The pressure outlet to the right had a pressure of $0 \mathrm{~Pa}$. The numerical modelling of the heatsink was performed using Reynolds-Averaged Navier-Stockes RANS equations, utilising $\mathrm{k}-\omega$ SST turbulence model. This turbulence model was 
chosen following the suggestions from ANSYS Fluent User Guide [25] and Alimohammadi et al. [26][28] who studied the effects and accuracies of turbulence models on heat transfer.

The analysis was based on the following assumptions:

1. The flow is steady, two dimensional, normal, uniform and incompressible across the fins in the xy plane.

2. Fluid properties are evaluated at film temperature.

3. The fins have a $99 \%$ efficiency.

4. The heatsink is surrounded by an infinitely free $2 \mathrm{D}$ environment.

5. Heat sources are within the fins and the temperature is uniform.

6. Natural convection and radiation contribute less than $2 \%$ and $7 \%$ of the total heat transfer and will be neglected for simplicity.

7. The fin material is homogeneous and isotropic.

8. The fin surface roughness is negligible and therefore a no-slip condition can be assumed.

\section{III.2 Geometry}

Table 1 lists the various heatsink dimensions. L represents the length of the Baseline (original) fin, 1 is the length of the shorter fins, $t$ is the thickness of the fins, $d$ is the gap between the fin columns, $b$ is the spacing between the fin rows and $g$ is the distance between the two halves of the heatsink.

Overall, four families of geometric variants with a total of twenty configurations were considered in this investigation. Each configuration will be consistently denoted with a unique name and abbreviated identifier.

The first family contains the Baseline and Double Cut, both illustrated in Fig. 2 (a) and (b) respectively. The former has ten fins that span the length of the heatsink, whereas the latter has 30 shorter fins divided into ten rows and three columns.

The remaining three families are inspired by the stream wise interruption design of the Double Cut configuration. It offers increased manoeuvrability of each fin, allowing for more diverse heatsink configurations and higher fin rotations. The new design undergoes the optimisation to determine the prime configuration angle of each of the 30 fins. The fins are modelled to rotate about their centre of axis, both in the clockwise and anti-clockwise directions. The degree of rotation is dictated by the gap between the fin rows and varies depending on the optimisation.

The second family, Input Parameter, consists of eight heatsink designs. This family is denoted by "IP", followed by an identifier number. This value of the identifier represents the number of groups the fins are divided into. For example, design IP 01 optimises all thirty fins using only one angle. IP 02 groups 
the fins in the upper half and lower half of the heatsink, each being optimised with a different fin angle, and so on. The concept of the Input Parameter family heatsink designs is depicted in Fig. 3.

The third family, Symmetrical, consists of four heatsink designs. Each design is labelled by "SY" followed by the design identifier. The SY Open design consists of the top and bottom five rows angled to form a "V" shape facing the direction of fluid flow. SY Closed is the inverse of SY Open, where the fins are angled away from the fluid flow. SY O-Zig couples the ten rows into five groups of two rows with each group creating a "V" facing the fluid flow. SY C-Zig is the again the reverse of SY O-Zig. Figure 4 provides visual illustrations of the designs starting orientation.

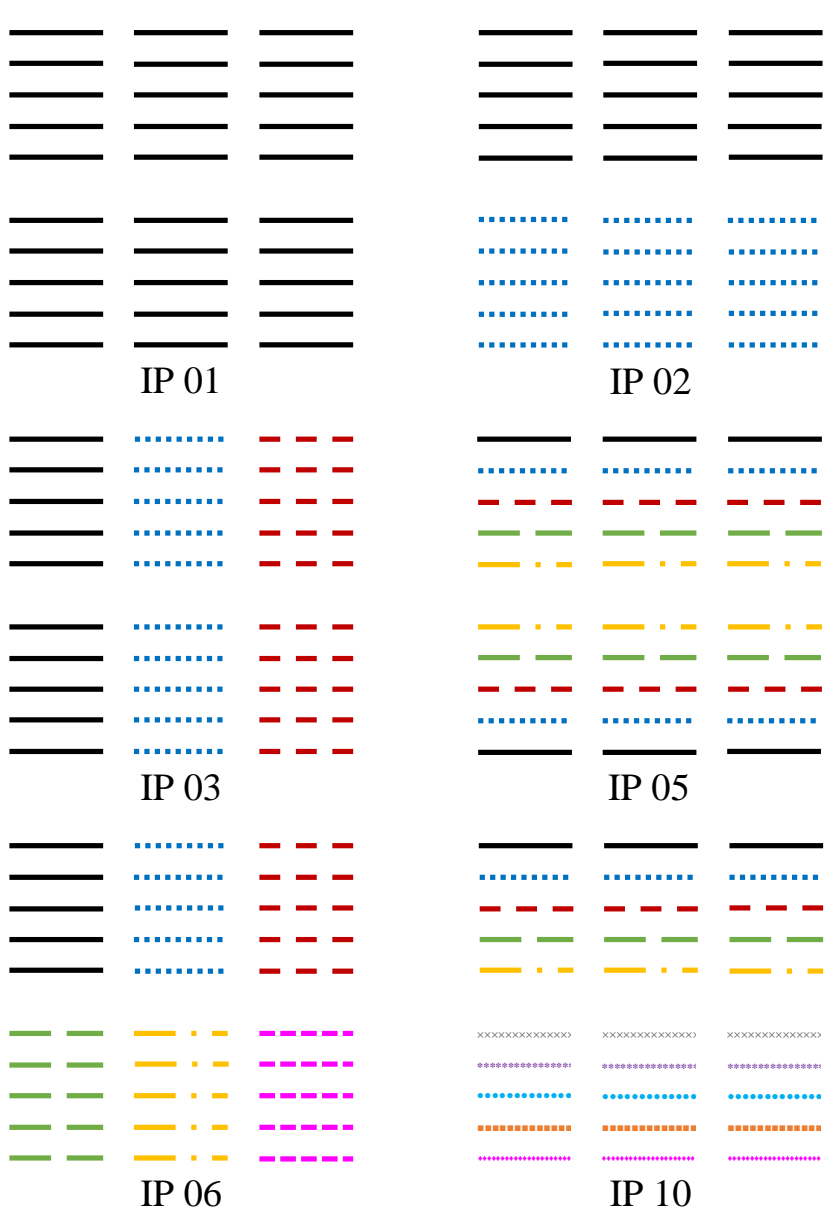

Figure 3: Input Parameter (IP) heatsink family 


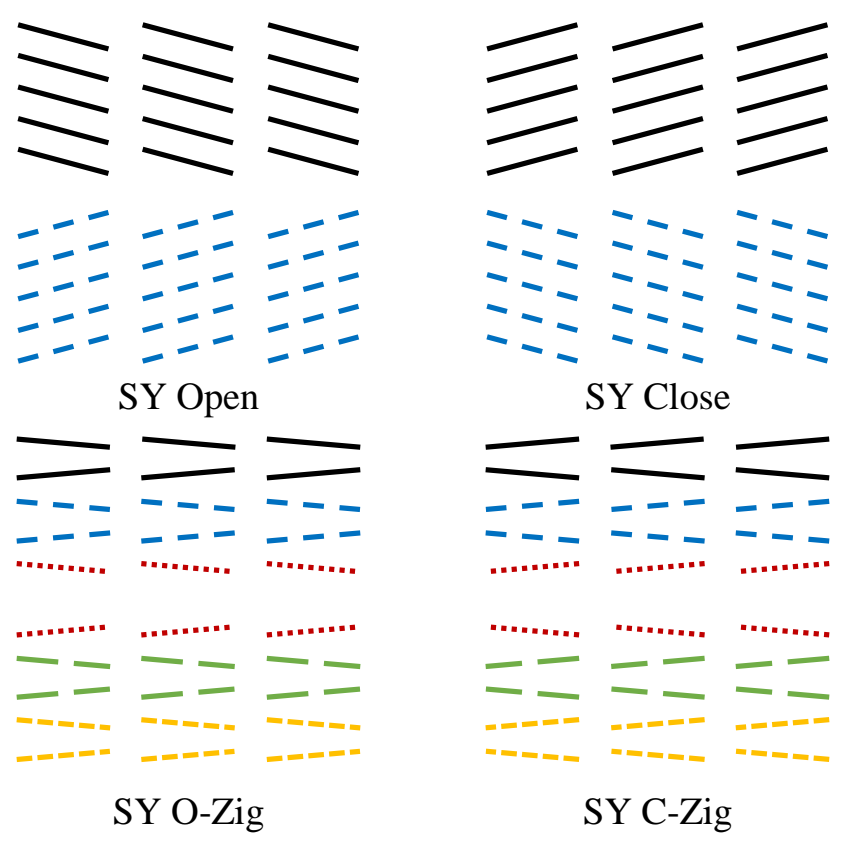

Figure 4: Symmetrical (SY) heatsink family

The fourth family, Fin Reduction, consisted of three different designs, arranged in two configurations. The heatsink designs are referred to by "FR" followed by the number of fins removed from each column. For example, design FR 024 has zero fins removed from the first column, two from the second, and four from the third. FR 464 has four fins removed from the first column, six from the second, and four from the third. The second configuration is merely the mirror image of the first, resulting in FR 420 and FR 646. The initial orientation of the six designs is outlined in Fig. 5.

Table 2 displays the angle range for all designs in the Input Parameter, Symmetrical, and Fin Reduction families.

Table 2: Fin angle rotation ranges for optimisation (IP = Input Parameter, $\mathrm{SY}=$ Symmetrical, FR = Fin Reduction)

\begin{tabular}{cccc}
\hline Design & $\begin{array}{c}\text { Angle } \\
\text { Range }\end{array}$ & Design & $\begin{array}{c}\text { Angle } \\
\text { Range }\end{array}$ \\
\hline IP 1 & $\pm 30^{\circ}$ & SY Closed & $\pm 15^{\circ}$ \\
IP 2 & $\pm 20^{\circ}$ & SY O-Zig & $\pm 05^{\circ}$ \\
IP 3 & $\pm 30^{\circ}$ & SY C-Zig & $\pm 05^{\circ}$ \\
IP 5 & $\pm 15^{\circ}$ & FR 024 & $\pm 15^{\circ}$ \\
IP 6 & $\pm 20^{\circ}$ & FR 420 & $\pm 15^{\circ}$ \\
IP 10 & $\pm 15^{\circ}$ & FR 048 & $\pm 15^{\circ}$ \\
IP 15 & $\pm 15^{\circ}$ & FR 840 & $\pm 15^{\circ}$ \\
IP 30 & $\pm 15^{\circ}$ & FR 464 & $\pm 30^{\circ}$ \\
SY Open & $\pm 15^{\circ}$ & FR 646 & $\pm 30^{\circ}$ \\
\hline
\end{tabular}




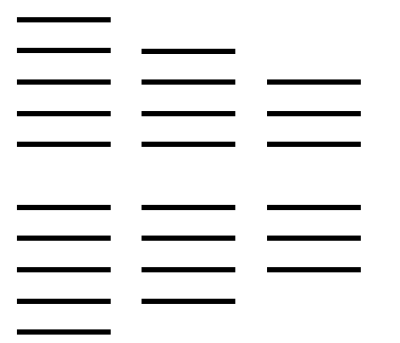

FR 024

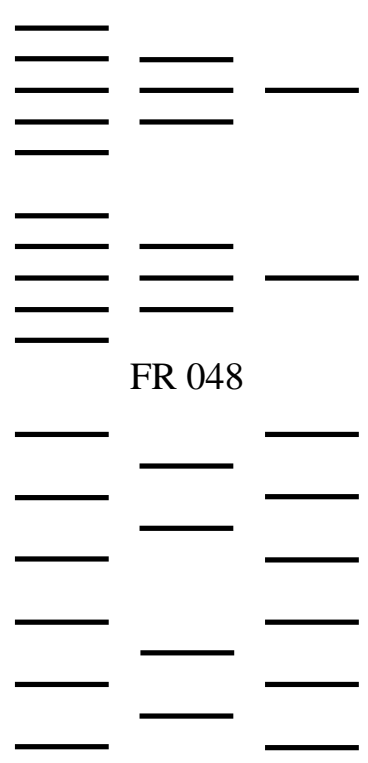

FR 464

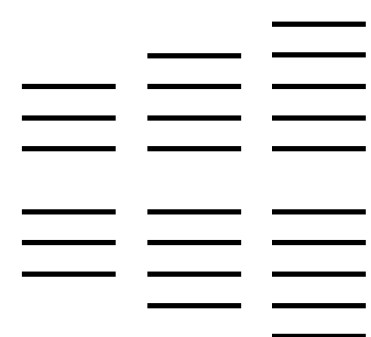

FR 420

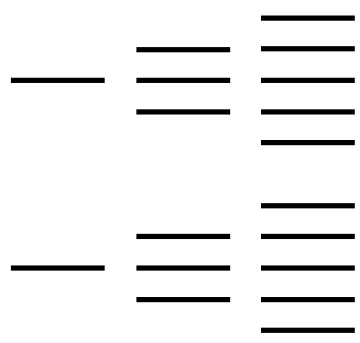

FR 840

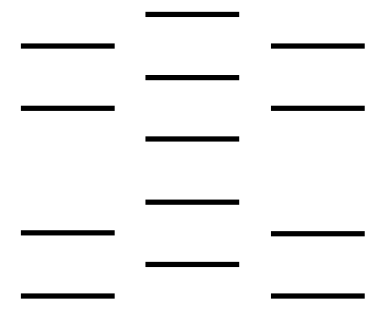

FR 646

Figure 5: Fin Reduction (FR) heatsink family

\section{III.3 Mesh Development and Independence Studies}

Considering the abundant amount of iterations that are computed in the optimisation loop, the mesh needs to be relatively small to reduce the computational time while still producing highly accurate results. The mesh should also function with the old and new heatsink design, in order to achieve a fair comparison between the two [18].

Figure 6 (a) presents how the flow domain was divided into two sections, each with different size parameters. A refined segment was created with small elements sizes to capture the flow entering and trailing from the heatsink. The outer areas are of no importance to the investigation and so the mesh nodes are left at higher element sizes, reducing the overall number of elements. 


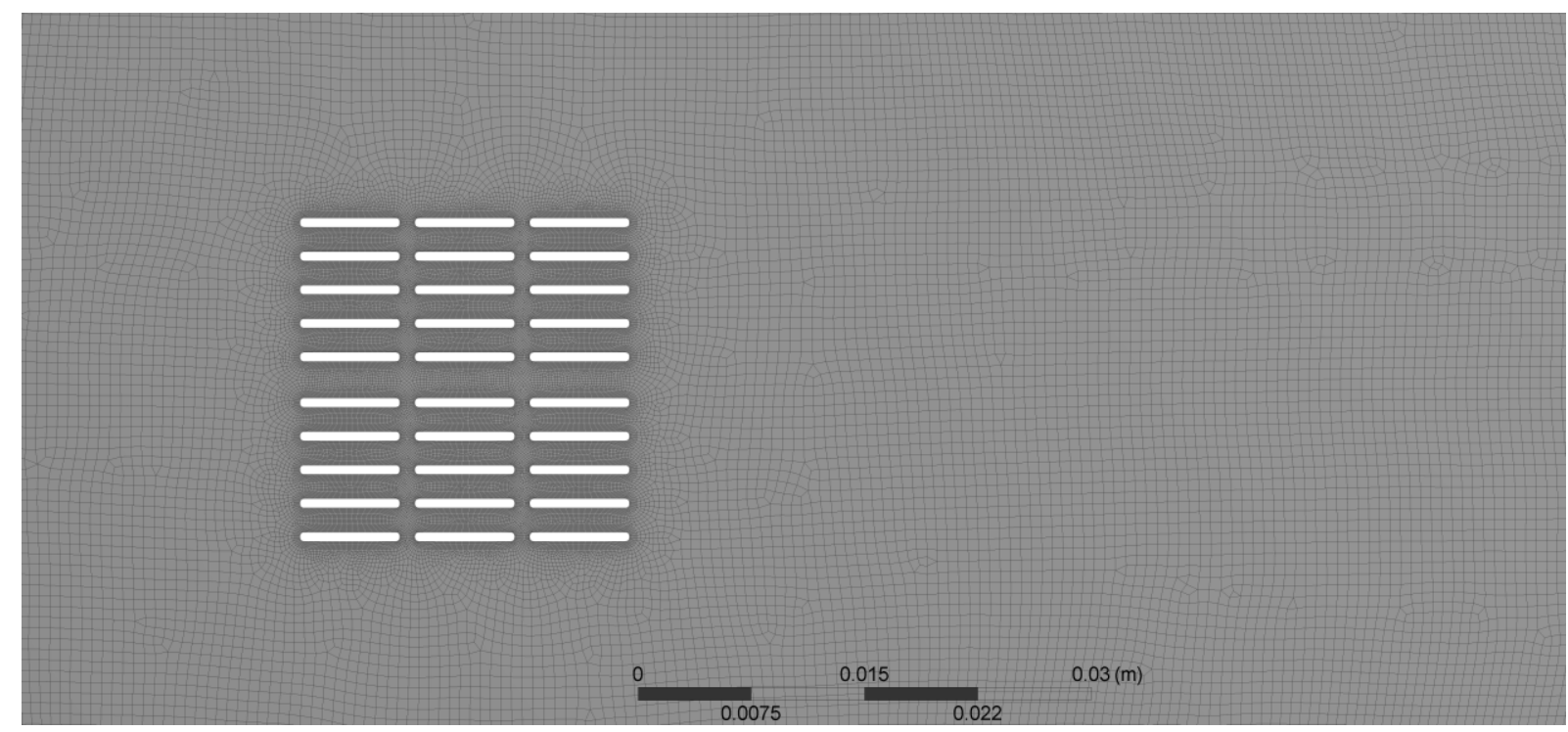

(a)

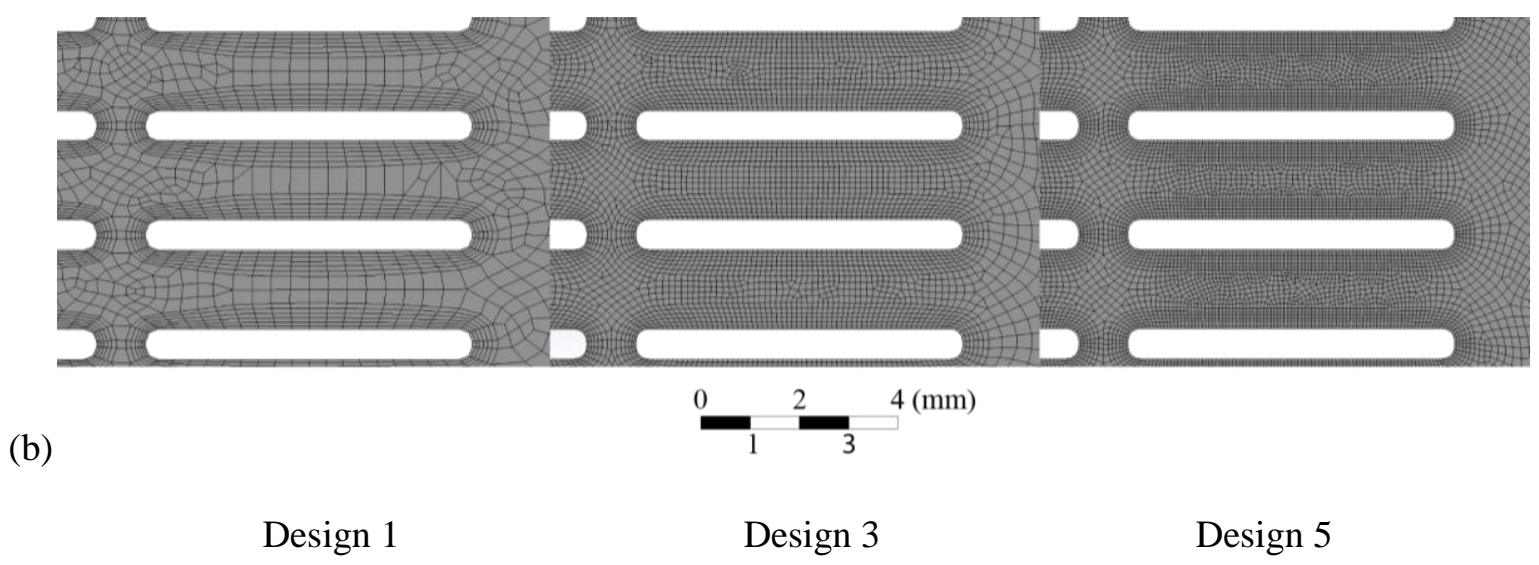

Figure 6: a) The mesh (Double Cut design example), b) Mesh comparison: Design 1, 3, and 5

Table 3 lists the range of the different parameters that were evaluated in choosing the optimal mesh. As the element sizes decrease, there is a noticeable increase in the time and number of iterations required for the solution to converge. The number of elements in the mesh also increases, linearly at first with a sudden jump at mesh 5. However, with the noticeable increase in mesh nodes, the average element quality and aspect ratio did not improve as much. The heat transfer rate stayed roughly the same. Nonetheless, mesh 3 appears to be the prime mesh out of the five. It balances the computational time and accuracy of the results. Even though the mesh quality is 0.85 , the average quality around the heatsink is 0.95 . A similar comprehensive sensitivity analysis of all of the selected parameters, including the mesh independency, is carried out for all of the investigated families of heat sinks, separately. Figure 6 (b) presents three of the five mesh referred to in Table 3. 
Table 3: Example mesh properties of Double Cut design (mesh independent results)

\begin{tabular}{lccccc}
\hline Mesh & Design 1 & Design 2 & Design 3 & Design 4 & Design 5 \\
\hline Fin edge sizing (m) & $3.5 \times 10^{-4}$ & $2.5 \times 10^{-4}$ & $1.0 \times 10^{-4}$ & $8.5 \times 10^{-5}$ & $7.0 \times 10^{-5}$ \\
Number of elements & 14,122 & 20,295 & 52,080 & 76,875 & 198,274 \\
Average element quality & 0.56 & 0.68 & 0.85 & 0.87 & 0.92 \\
Average aspect ratio & 3.16 & 2.5 & 1.23 & 1.15 & 1.09 \\
Heat transfer rate (W) & 6.767 & 6.801 & 6.787 & 6.790 & 6.788 \\
\hline
\end{tabular}

The first layer thickness, $7.0 \times 10^{-5}(\mathrm{~m})$, is determined using $\mathrm{Y}^{+}=1$. The first layer of inflation is influenced by the Reynolds number, characteristic length and the viscosity of the fluid. A specific case study on the first layer thickness is essential to accommodate all potential fin configurations to prevent the need for regenerating the mesh for different tests. A suitable number of inflation layers from the walls is also required to capture the entire flow between the fins without any overlaps that could cause the mesh to fail. This number needs to be high enough to provide accurate results of the fluid flow in the viscous sub-layer, even when fins are rotated. The inflation layer parameters are all tested separately. After multiple trial and error examinations, the optimum inflation parameters are derived and kept constant for the rest of the mesh evaluation. The best mesh selected as a result of a comprehensive case study through various refinements is composed of 52,080 elements [18].

An edge sizing was also added to the fins to increase the number of cells around the edges and using a suggested growth rate of 1.2. This helps to reduce the aspect ratio to an acceptable value under 5:1. Improving the aspect ratio and skewness of the cell nodes will help the convergence.

\section{III.4 Optimisation Loop}

The multi-objective genetic algorithm (MOGA) uses a direct optimisation methodology to solve for a specific requirement. GAs have been used for the optimization of heat exchangers of various sizes [17]. MOGA generates an initial sample population based on the primary parameters and the constraints set by the user. The larger the initial sample set, the better the chances of finding the input parameter space that contains the best solution. However, the larger the initial sample population, the more computational time required to complete these calculations [18].

Figure 7 highlights the evaluation cycle of the optimisation loop. The input parameters, i.e. the angles of the fins, vary within the upper and lower limits and generate the initial population. MOGA solves all samples in the initial population and selects the best candidates. This is done by slightly varying the parameters of the prime candidates from the first generation and using them to initialise the second population. The second generation is solved and the best candidates are selected again to breed the third 
generation. This process continues until the desired number of evaluations is reached or until the solution converges on the optimum input parameter configuration [18].

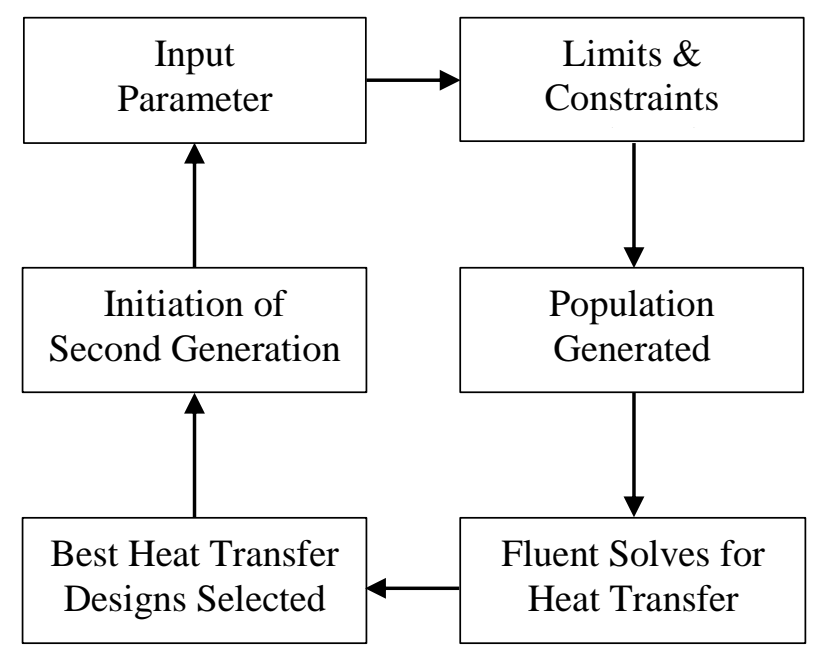

Figure 7: Evaluation cycle for the optimisation loop

\section{III.5 Genetic Algorithm}

The genetic algorithm is initiated by generating the sample population based on the angle constraints. The algorithm arbitrary picks an angle to start with. In the case of IP 10 , it was $-14.85^{\circ}$. This angle changes for each of the numbers of input parameters. Ten angles for each of the ten rows, with 100 configurations generated for the initial population and 50 thereafter.

The optimisation process is seen in Fig. 8 with the sudden jumps every 50 evaluations. This marks the beginning of the new generation when the prime candidates who achieved the highest heat transfer in the previous generation are slightly modified in an attempt to improve their performance until the evaluation has converged on one solution.

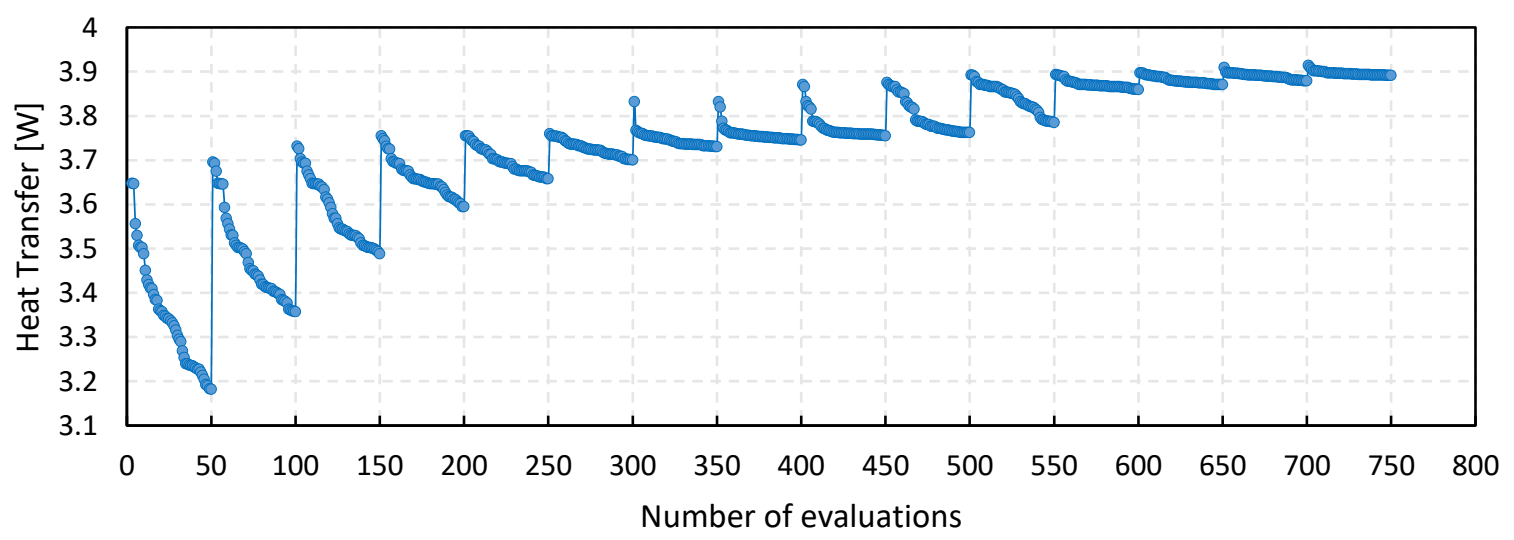

Figure 8: Heat transfer progression through the generations (for IP 10) 
Figure 8 also highlights the enhancement in the heat transfer as the evaluation number advances, while decreasing within each generation. This is depicted in Fig. 9. It displays how the difference in the angle configuration is reduced with each stage in the cycle, for the initial population, i.e. $0^{\text {th }}$ generation, the $5^{\text {th }}$ generation after 250 evaluations, the $10^{\text {th }}$ generation after 500 evaluations, and the final configuration in the $15^{\text {th }}$ generation at evaluation number 781 . These evaluations are accompanied with the following heat transfer rates: $3.65 \mathrm{~W}, 3.76 \mathrm{~W}, 3.89 \mathrm{~W}$, and $3.91 \mathrm{~W}$ respectively.
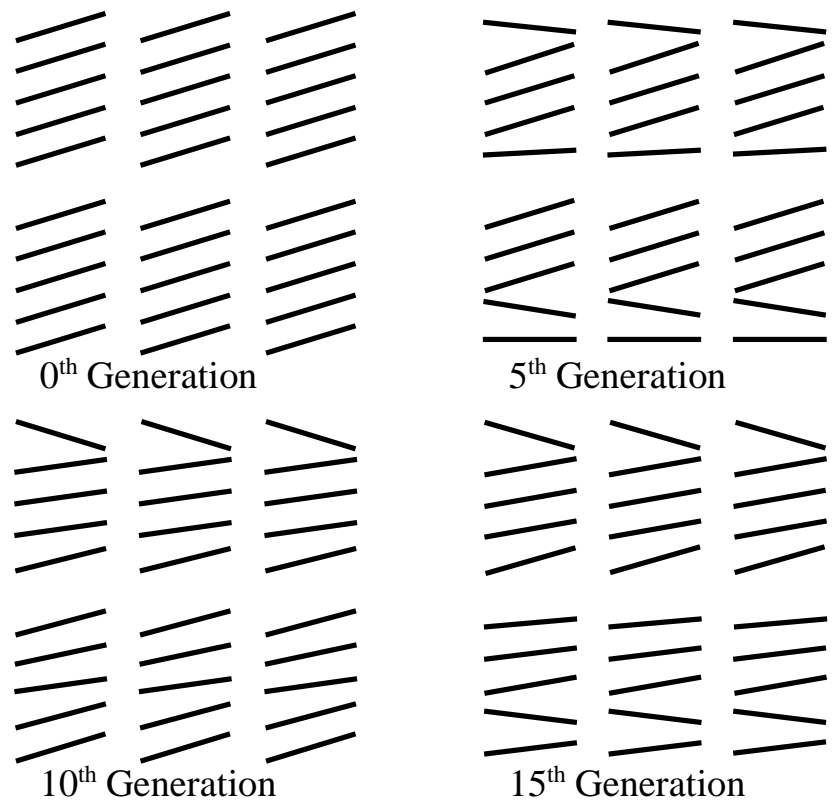

Figure 9: Genetic algorithm progression through the generations for design IP 10

\section{III.6 CFD Model Setup}

Due to computational time constraints, only one objective function, i.e. heat transfer rate, is used. The optimisation loop chosen in this project is limited to 100 initial samples, 20 iterations consisting of 50 samples per iteration and the optimisation convergence criterion of $2 \%$ [18].

The number of Input Parameter simulated is limited to 1, 2, 3, 5, 6, 10, 15 and 30. The number of Fin Reduction simulations and the Symmetrical simulations are limited to six and four respectively [18].

The optimisations are also simulated under steady-state conditions to obtain a rough estimate of the prime angle configurations whilst requiring less computational time. The angles obtained from these simulations are then modelled under transient time using a time step size of 0.001 seconds, 1,000 time steps and a maximum of 20 iterations per time step. This ensures the convergence and accuracy of the results. The transient simulation convergence criteria is set at $10^{-4}$ for velocity components and at $10^{-6}$ for the energy equation. The numerical simulations are validated with the analytical results derived using Teertstra et al. [21] 2D, parallel plate theory, as reported in [18] and [26]. 


\section{Results and Discussion}

\section{IV.1 Heat Transfer Performance}

Figure 10 (a) depicts a clear image of how the various heatsinks designs performed against each other in regards to their heat transfer rates. The Baseline heatsink marks the benchmark performance with a heat transfer rate amounting to $3.31 \mathrm{~W}$. The initial improvement, the creation of the Double Cut design results in a significant heat transfer rate performance increase with a value of $11.2 \%$. A heat transfer rate range of $3.72-3.91 \mathrm{~W}$, or $12.4 \%-18.1 \%$ over the Baseline design is observed from the results of the Input Parameter optimisation methodology.

A heat transfer rate improvement was anticipated as the designs of the Input Parameter category gradually increased the number of input parameters used. It was expected that with a wider diversity of fin configurations, the heatsink performance would increase. However, the results provided otherwise. The heat transfer rate may have very well been hindered by the limited size of the initial sample population, amounting only to 100 , that was used in the algorithm. The majority of the optimal angles identified by the genetic algorithm were more or less the same for the eight designs. Perhaps the limited pool of primal designs and a low number of generation iterations constrained the genetic algorithm in finding the optimal fine angles for each of the Input Parameter designs. Nonetheless, all of the configurations achieved results that were significantly higher than the Baseline heatsink. However, the enhancement over the Double Cut design was not as good as envisioned.

The performances of the Symmetric optimisation designs did not achieve the same degree of heat transfer rate improvement that was observed with the Input Parameter method. The performance of the Symmetric designs was so poor that they even yielded lower heat transfer rates than those produced by the Double Cut design. However, three of the four designs were able to perform better than the Baseline, the exception being SY C-Zig.

SY Open was expected to perform better than the others as open fins have the ability to capture more fluid from the stream, channelling it to the core of the heatsink as seen in Fig. 4. However, with a heat transfer rate of $3.47 \mathrm{~W}$, the heatsink dissipates $5.7 \%$ less than the unaltered Double Cut design.

Similarly, the SY O-Zig and SY C-Zig produced surprising results. This configuration was expected to agitate the fluid flow, and thus, improving the heat transfer rate. However, the opposite effect was obtained. The reason behind this could be attributed to the configuration of the fins. Since the entire row is moved symmetrically, the fluid flow was constrained, reducing its velocity and limiting the amount of fluid flowing past the fins which will, in turn, reduce the heat transfer rate. 
With the added complexity of manufacturing heatsinks with angled fin, these designs are expected to perform considerably better to justify the additional costs incurred at the expense of manufacturing difficulty.

The results from the Fin Reduction category proved to be the most interesting as design FR 024 outperformed the others with a heat transfer of $3.42 \mathrm{~W}$. This is higher than the Baseline by $3.3 \%$ but lower than the Double Cut by $7.1 \%$. However, considering that this design has six fewer fins, it highlights the configuration's potential. Especially by having a smaller surface area than the other designs. The other two designs have performed better than their mirror images, however, there were not able to achieve the same level of heat transfer rate. This again is a result of having twelve and sixteen, and fourteen fewer fins in the FR 048 - FR 840 and FR 464- FR 646 respectively.

Comparing the Fin Reduction designs with the other is unjust, especially considering that they have a smaller surface area to dissipate heat. As a result, a mass metric was devised to compare all the results on a fair basis. Each of the design's heat transfer values are divided by their mass and the results are illustrated in Fig. 10 (b). Using the mass metric, the heat transfer results display a similar ratio between them, as seen in Fig. 10 (a). 


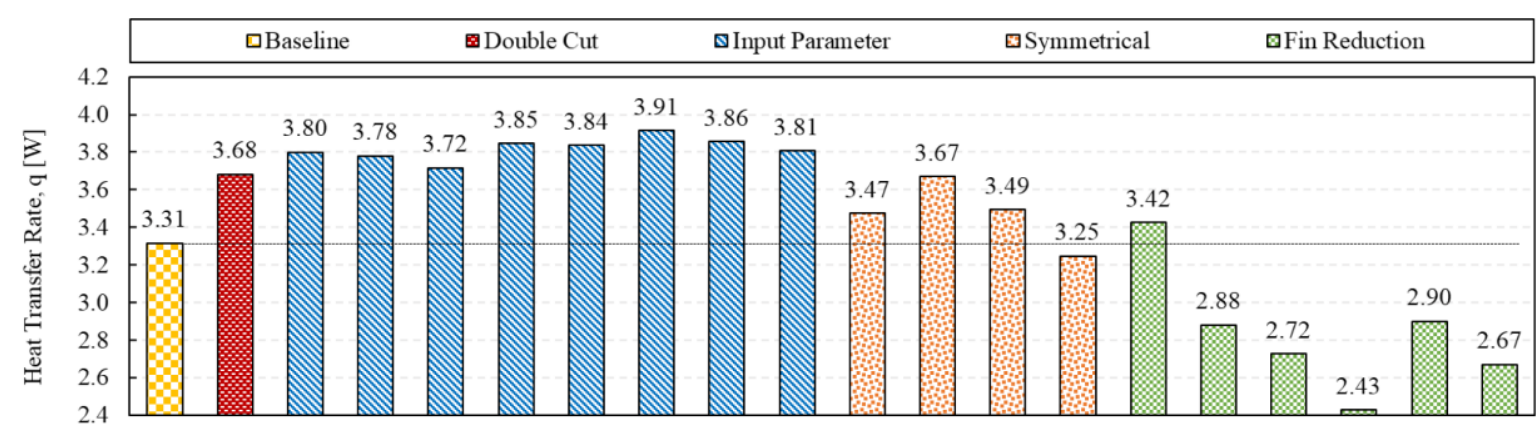

(a)

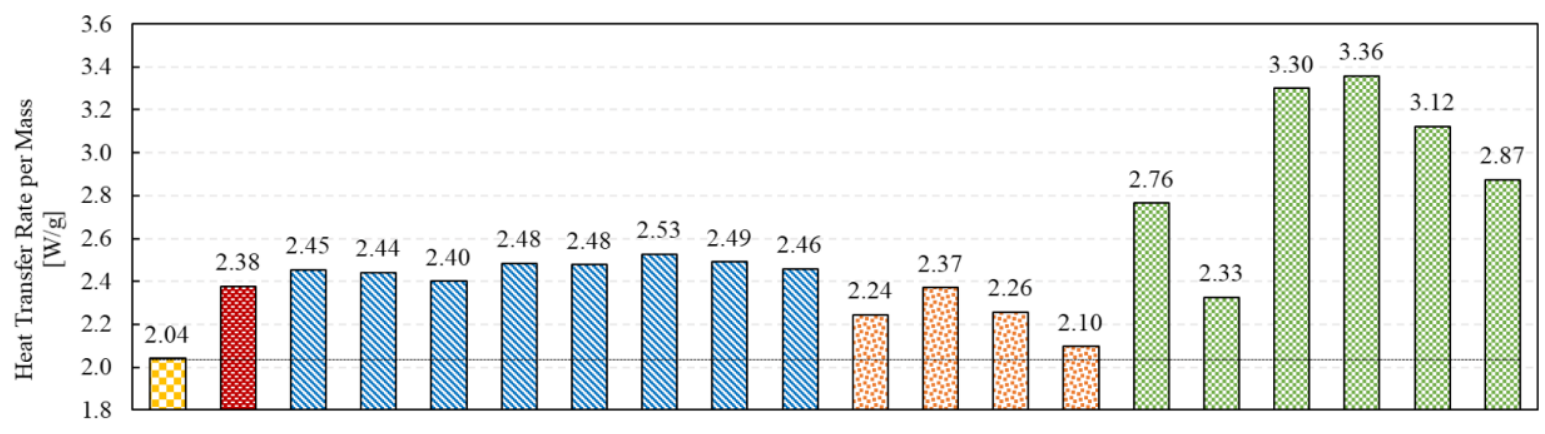

(b)

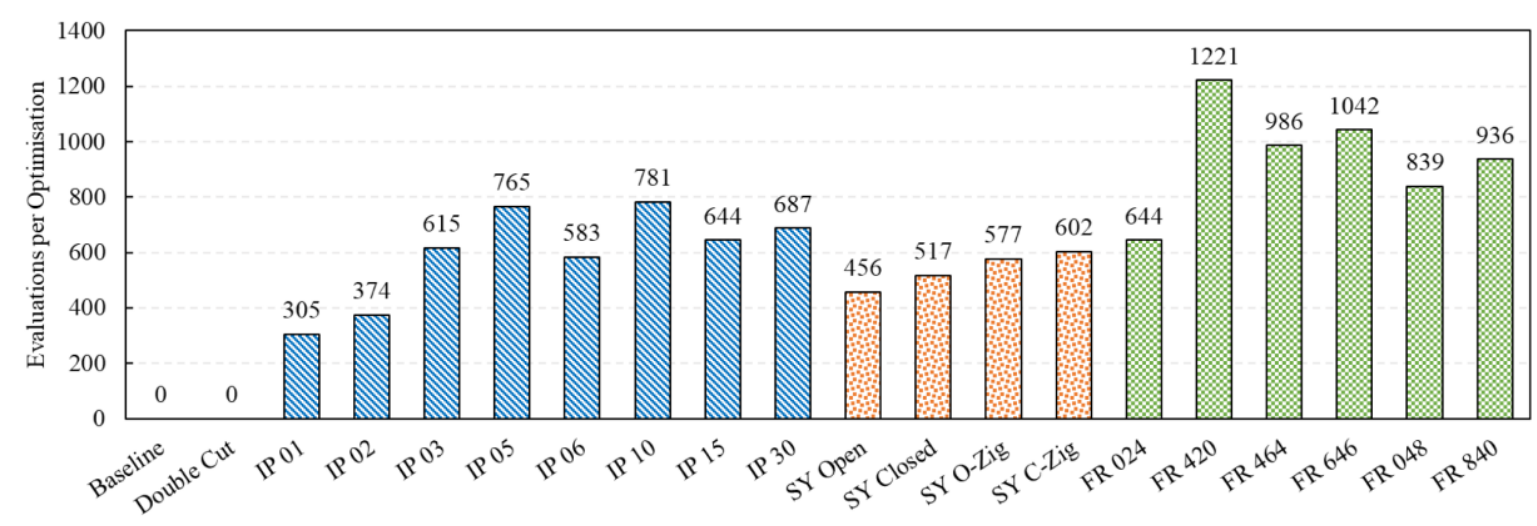

(c)

Figure 10: Overview of heat transfer rate for each optimized geometric variant, (a) Normal, (b) Per mass, (c) number of evaluations per optimisation

The Double Cut design is considerably higher than the Baseline, the Input Parameter designs are slightly higher than the Double Cut design, and the Symmetric are lower than the Input Parameter results. The only surprise is noticed in the Fin Reduction category, which prevails when their surface area was considered.

The lowest heat transfer rate per mass is almost identical to that of Double Cut, with a value of $2.3 \mathrm{~W} / \mathrm{g}$. The other five designs obtained higher values with the lowest being FR 024, with a value of $2.8 \mathrm{~W} / \mathrm{g}$, which is 35.3\% higher than the Baseline and 9\% higher than IP 10. The most surprising result is from design FR 646, which had the lowest heat transfer rate. Now, with a value of 3.4W/g, it is $65 \%$ higher than the Baseline heatsink and 32.8\% higher than IP 10. 
Figure 10 (c) shows no clear trend for the number of evaluations required for each of the methodologies. However, a gradual increase can be seen spanning from IP 01-05, considering the increase in the number of variables and possible configurations to be processed.

The mirror images of each of the Symmetrical and Fin Reduction designs had a higher number of evaluations compared to their normal configuration. This increase, at least for the Fin Reduction designs, can be attributed to the majority of the fins being located at the trailing end of the heatsink as shown in Fig. 5. Since the majority of fins are located at the back, any changes in the front fins will have a drastic impact on the orientation of the rear fins. The genetic algorithm will, therefore, generate more configurations for the rear fins, explaining the reason behind the increased time.

From Fig. 11 (a), a large cluster is evident indicating very little difference between the eight optimisations. This is not surprising as their heat transfer rates deviate very little from each other. Nonetheless, the optimisation with the least thermal resistance is IP 10, which is expected considering that IP 10 has the highest heat transfer rate.

From Fig. 11 (b), the SY Closed design has the lowest thermal resistance. This is expected as it has the highest heat transfer of the four designs. The SY C-Zig design trails in the last place, whereas the SY Open and SY O-Zig are competing for second. The SY Open configuration performed better at higher velocities whereas the SY O-Zig performed better at lower velocities. This can be attributed to the agitating nature of the SY O-Zig configuration. Some of the channels, as seen in Fig. 4, hinder the fluid motion due to the small gaps between the fins.

Figure 11 (c) shows rather interesting results with a wider variation in thermal resistance. The figure indicates that design FR 024 has the lowest thermal resistance. Although that may be true, this is the most difficult category for comparison, considering that each configuration has a different number of fins and thus different surface areas to dissipate heat from. In order to compare them fairly, the heat transfer per mass was used.

Factoring the difference in the number of fins in each configuration, a different distribution is seen from Fig. 12 for the thermal resistance per mass for the Fin Reduction family.

The FR 420 design was the best and now it is one of the worst. The design with the lowest thermal resistance per mass is FR 646 followed by a close second with its inverse image FR 464. All the thermal resistance per mass start off very high at a Reynolds number of 170, but they are significantly reduced into a cluster when the Reynolds number is increased to 507. At this value, there is still a difference in the performance between them. However, it is not as drastic as it was when the Reynolds number was lower. It is, therefore, harder to say that one design is significantly better than the other. 


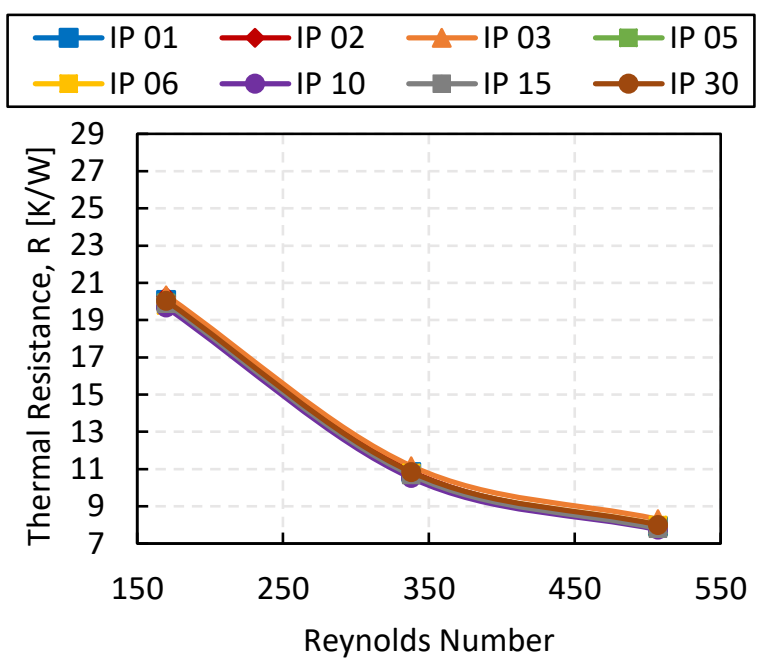

(a)

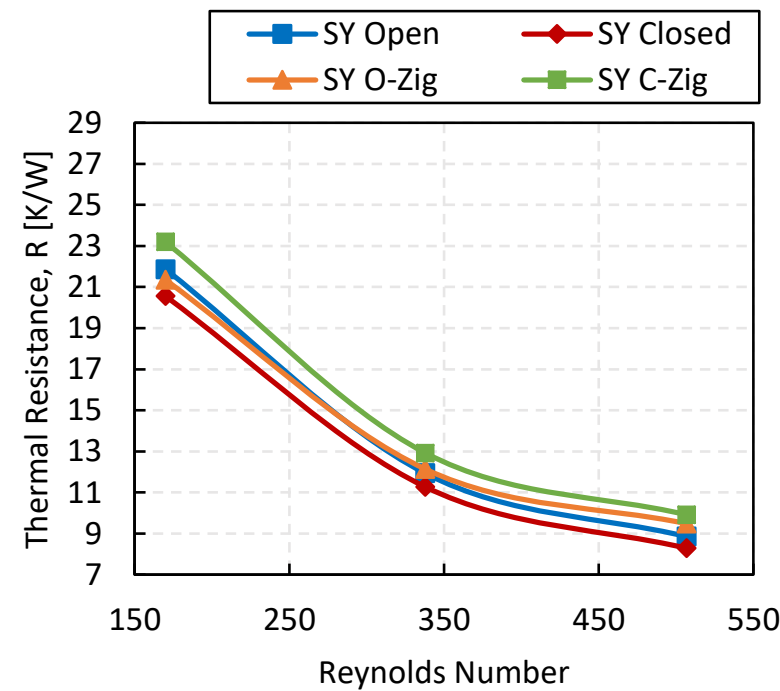

(b)
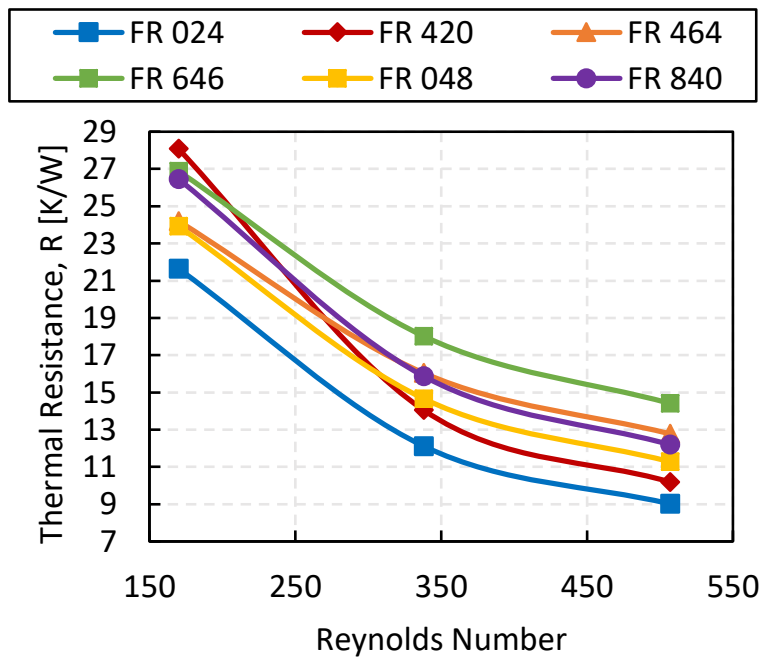

(c)

Figure 11: Thermal resistance for (a) Input Parameter (IP), (b) Symmetrical (SY), (c) Fin Reduction (FR) heatsink families 


\begin{tabular}{lll|}
- -FR 024 & -FR 420 \\
- -FR 646 & - FR 464 \\
\hline
\end{tabular}

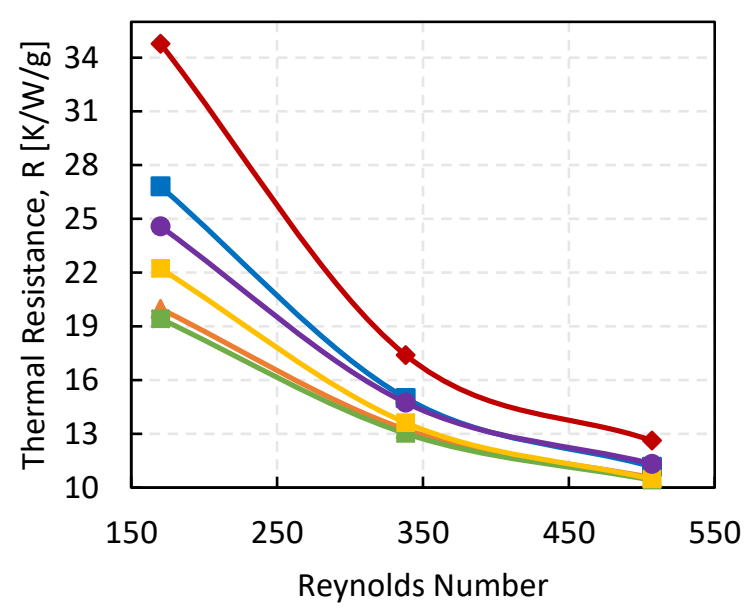

Figure 12: Thermal resistance per mass for the Fin Reduction family

The comparison of different families in terms of the thermal resistance per mass metric is illustrated in Fig. 13. All the simulations achieved a lower thermal resistance than the Baseline which can be considered a success in the optimisation methodology. Design FR 646 significantly outperforms the others, with IP 10 slightly behind along with the SY Closed design. Just like before, the thermal resistance is highest at the low velocities and decreases as the velocity increases, bridging the gap between the designs.
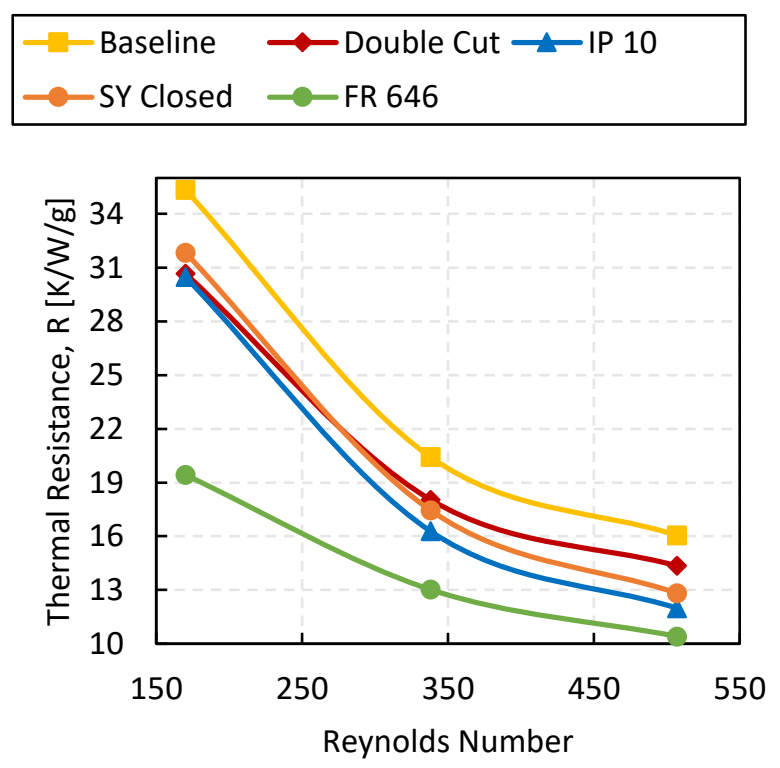

Figure 13: Thermal resistance per mass comparison 


\section{IV.2 Relationship between Heat Transfer Performance and Flow Characteristics}

Recalling that the turbulence intensity was set to $5 \%$ in the boundary conditions, Fig. 14 (a) shows nominal results for Baseline; it is a simple design oriented normal to the flow and so, the intensity is low. The Double Cut design has a slightly higher intensity, but this can be attributed to the boundary layers reforming after each fin. For the remaining configurations, the intensity fluctuates depending on the configuration of each design, mainly attributed to the angles determined by the genetic algorithm. The only unusual result is SY Closed with a value of $4.8 \%$. This is lower than the initial boundary condition and could attribute to the angle of the fins constricting the flow and forcing it to become laminar. It can, therefore, be deduced that there is no correlation between the heat transfer and the turbulence intensity. This justifies that the intensity is independent of the heat transfer and dependent on the angle configuration.

The results for the pumping power can be seen in Fig. 14 (b). The Baseline shows nominal results. It is a simple design, oriented normal to the fluid flow and so, produces a small pressure drop. The Double Cut has slightly higher pumping power which is attributed to the boundary layers reforming after each fin as a result of the fin gaps. The pumping power fluctuates for the remaining designs in conjunction with the complexity of the angles generated by the algorithm. The more complex the angle arrangement is, the more resistance the fluid endures to pass through the heatsink, needing more power to overcome the pressure drop.

Regarding the coefficient of performance, the Baseline sets the benchmark for Fig. 14 (c) at 1,496, with the majority of the heatsinks falling below it. The FR 024 and 420 configurations performed better than the Input Parameter and Symmetrical optimisations. This can be attributed to the fewer fins. However, they still perform worse than the Baseline. The remaining four designs performed higher than the other designs, with design FR 646 excelling by $58.6 \%$ over the Baseline.

When weight is considered, the Fin Reduction designs have both higher COP and heat transfer rates, as shown in Fig. 15. They possess many advantages over the other designs as a result of the fewer fins quantity. Each of the fins has the ability to rotate to larger angles, encouraging boundary layer separation and inducing further fluid mixing. The Fin Reduction designs reduce the pressure drops as a result of fewer interactions between the fluid and the fins. This, in turn, reduces the pumping power and consequently increases the COP.

Looking at the Baseline design in Fig. 16 (a), the momentum boundary layer develops and increases along the heatsink outer fins. The momentum boundary layer is almost stagnant, preventing the fluid from mixing and evidently reducing the heat transfer. The fluid departs the heatsink before transitioning from laminar to turbulent. This is reflected in the thermal boundary layer, where the temperatures flow field is a very close match to the velocity. 


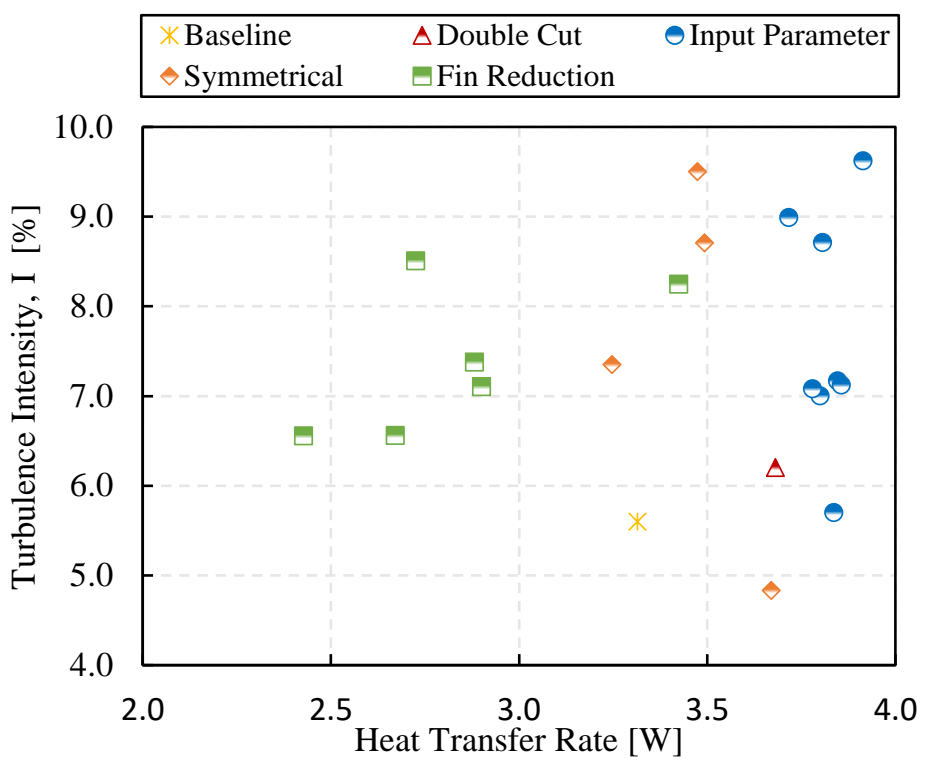

(a)

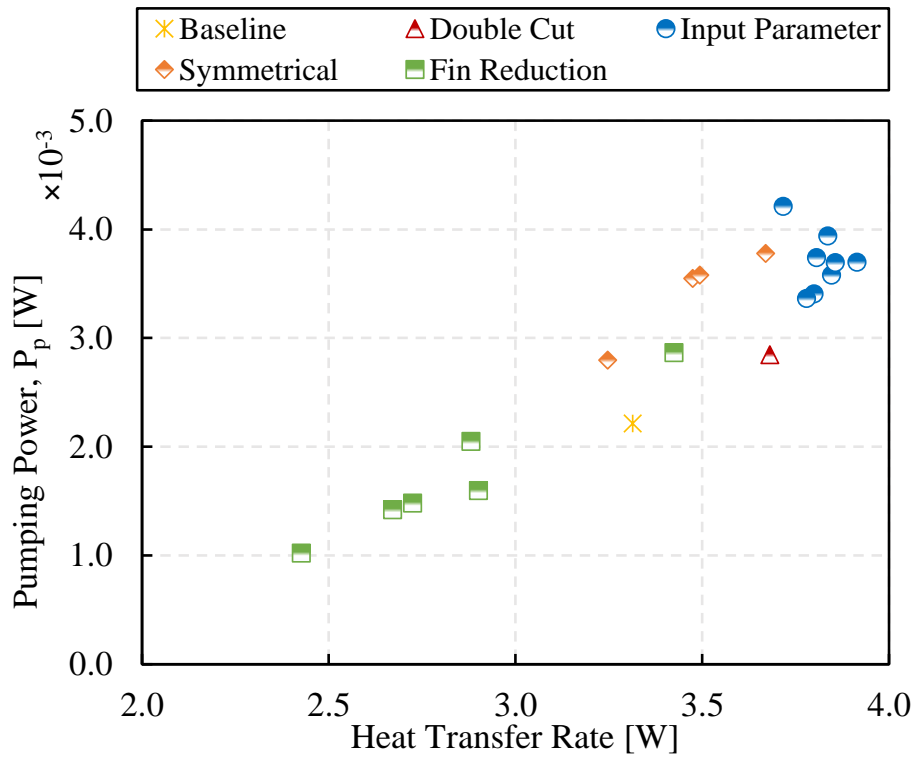

(b)

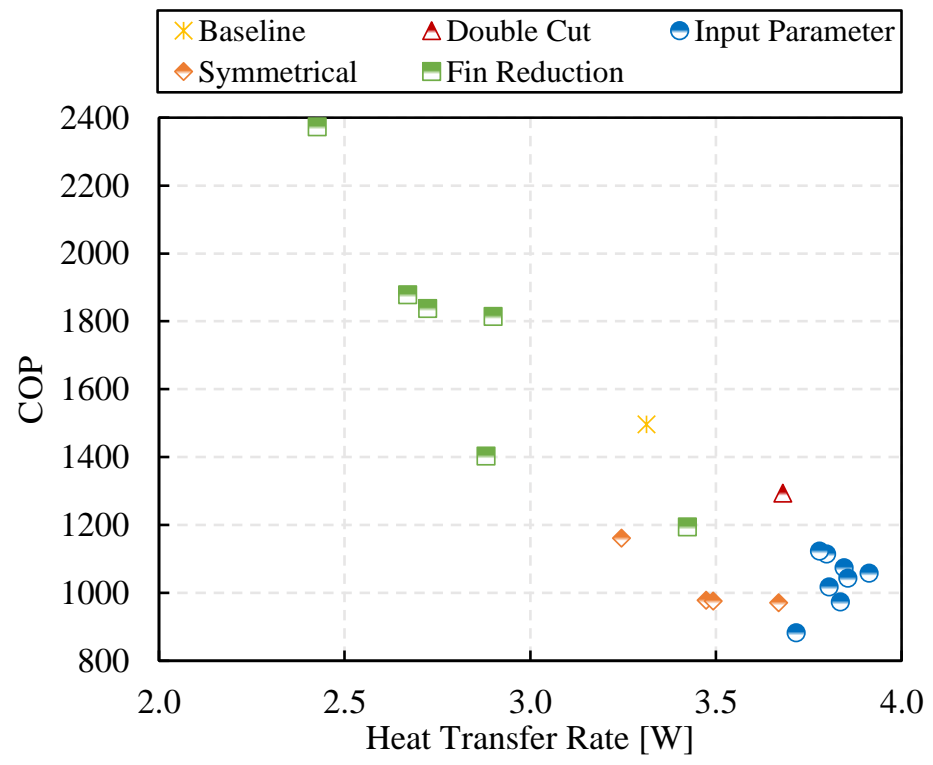

Figure 14: (a) Turbulence intensity, (b) Pumping power, (c) COP as a function of heat transfer rate 


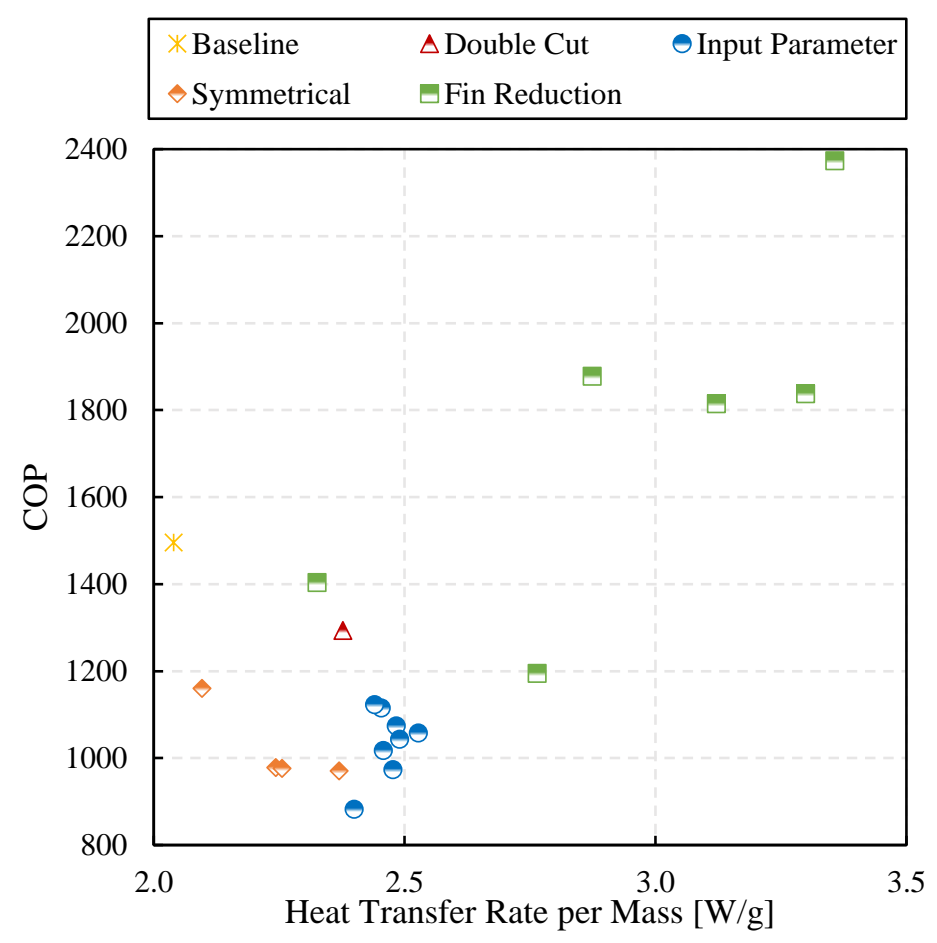

Figure 15: Coefficient of performance as a function of heat transfer rate per unit mass

The Double Cut design attempted to introduce turbulence with its three shorter fins. Although the velocity flow field from Fig. 16 (b) followed a similar pattern to the Baseline heatsink, the gaps between the fins helped the fluid inside the heatsink to escape and interrupt the boundary layer on the outer fins. This interruption increased the boundary layer thickness and caused it to be more subject to perturbations, which helped the fluid enter the transition region. This introduced further mixing and is responsible for the increase in the heat transfer. This is evident in the thermal boundary layer, where the fluid around the outer fins is at a much higher temperature compared to the Baseline heatsink. However, the fluid is still laminar, with room for improvement.

IP 10 attempts to finally bring about turbulence with its rotating fins. As seen in Fig. 16 (c), the angled fins interrupt the fluid significantly, causing the fluid flow to spin around the fins, mixing more and dissipating heat much more effectively. The boundary layer by the outer fins has separated as a result of the highly inclined angle configuration. This separation improved the heat transfer by increasing the turbulent kinetic energy around the fins. This is evident in the thermal boundary layer where the fluid surrounding the outer fins is hotter compared to those recorded for the Baseline and Double Cut designs. However, as a result of the boundary layer separation, a wake has been generated, trailing behind the heatsink. This is the cause of the reduction of the COP.

From Fig. 16 (d), the orientation of the SY Closed has significantly reduced the boundary layer thickness along the fins, which hindered the heat transfer by forcing the fluid to remain laminar, impeding the mixing. This was also noticed in Fig. 14 (a) with a turbulence intensity value of $4.8 \%$, which was less than the specified $5 \%$ as a boundary condition at the inlet velocity. 
(a)

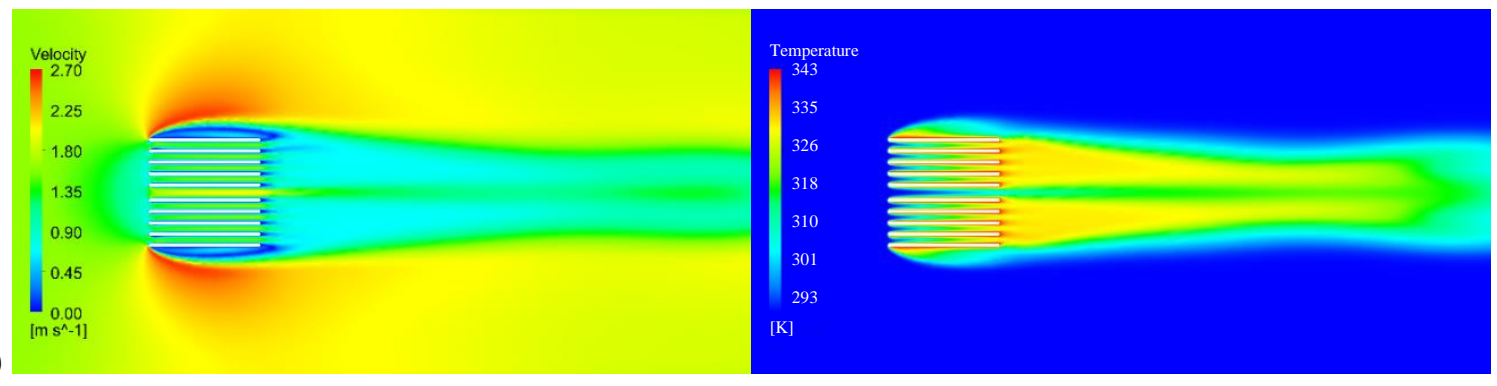

(b)

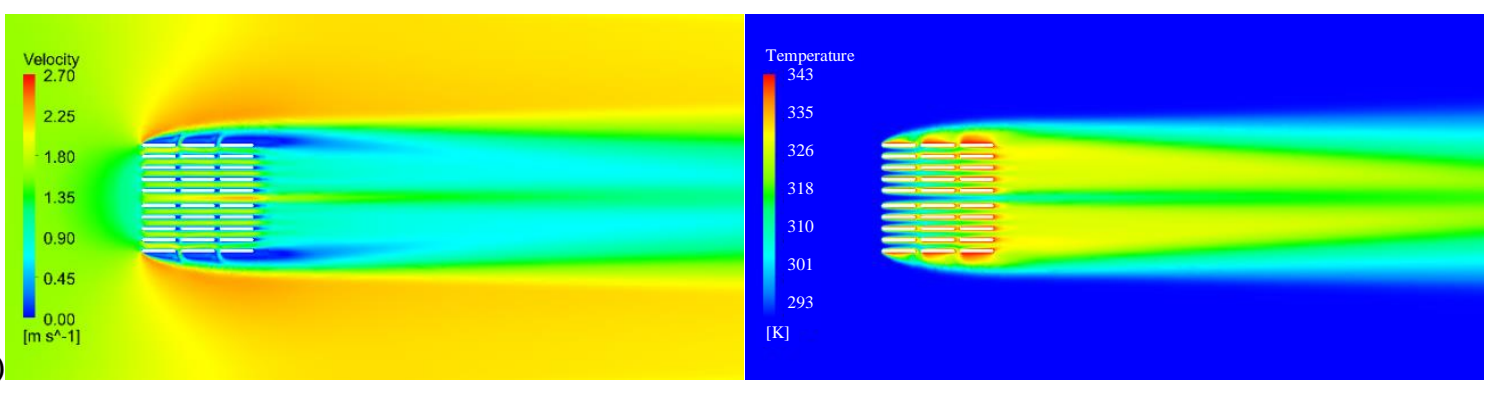

(c)

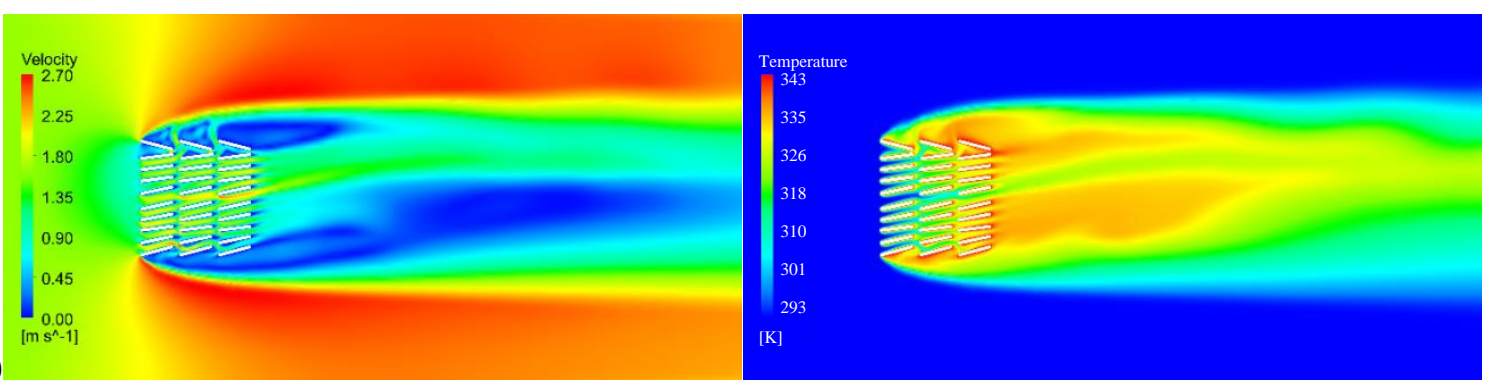

(d)

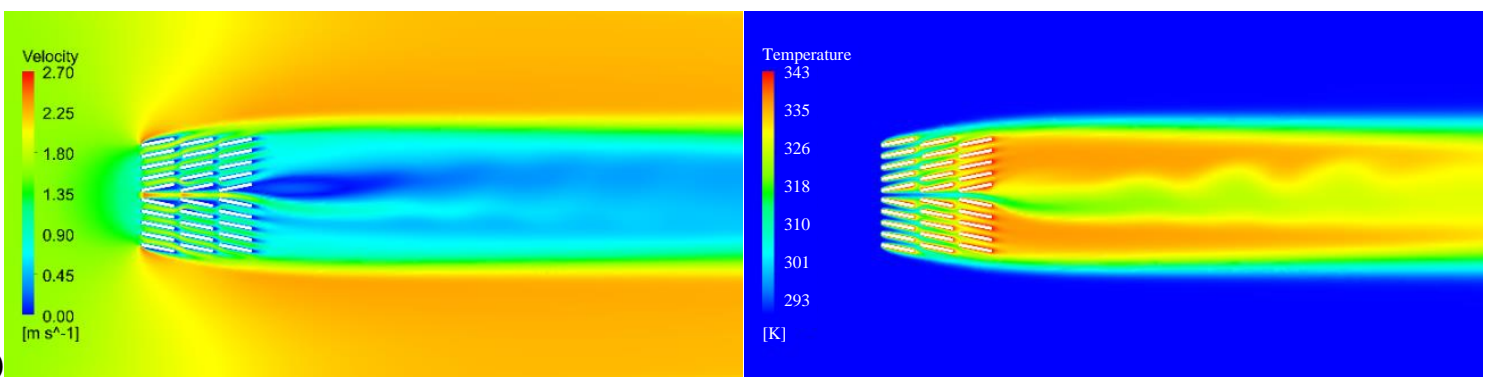

(e)

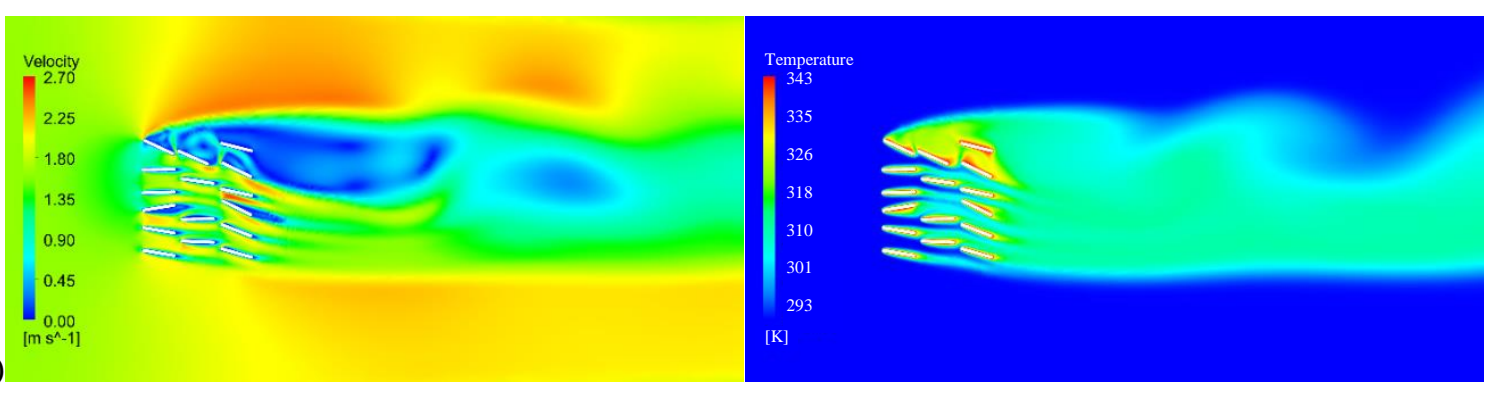

Figure 16: Flow velocity (left) and temperature (right) fields for heatsink designs (a) Baseline, (b)

Double Cut, (c) IP 10, (d) SY Closed, (e) FR 464

In the SY Closed configuration, the heatsink has forced the fluid confined by its walls to absorb more heat. In addition, the orientation of the fins has forced the already heated fluid to channel its way to the final column of fins. The now smaller temperature gradient between the fluid and the rear fin walls 
reduces the efficiency of the heat transfer. The fluid trailing behind the heatsink is at a considerably higher temperature compared to the Double Cut design, Fig. 16 (b), which shares an almost identical heat transfer. However, this increased temperature of the fluid in SY Closed configuration is caused by a lower heat transfer coefficient rather than an improved heat transfer rate, which resulted in the fluid to absorb more heat.

Due to its ability to achieve higher angles, design FR 464 has successfully induced the expected turbulent behaviour. This is evident from the vortices shedding from the heatsink. From Fig. 16 (e), the entire upper row is highly inclined with vortices forming around them. This has increased mixing which is visible in the thermal boundary layer, where the fluid in the upper region is at a much higher temperature compared to the rest of the heatsink. This increased mixing which improves the heat transfer rate. However, because of the reduced fins, the heat transfer rate is not as high as the other designs.

The Chilton-Colburn j-factors provide a useful correlation of the data for any two transport processes near flat surfaces and proved to be the most accurate. Figure 17 summarises the entire discussion behind the twenty heatsinks simulated in the research. It utilises the $\mathrm{j}$-factor for both heat and friction, where it factors in the heat transfer and the pressure drop as two of the most important factors associated with the performance of a heatsink. Since the goal is for a high heat transfer and a low-pressure drop, anything above the linear fit line is better than average. Designs to the left are better as a result of a lower pressure drop and designs to the top indicate a higher heat transfer.

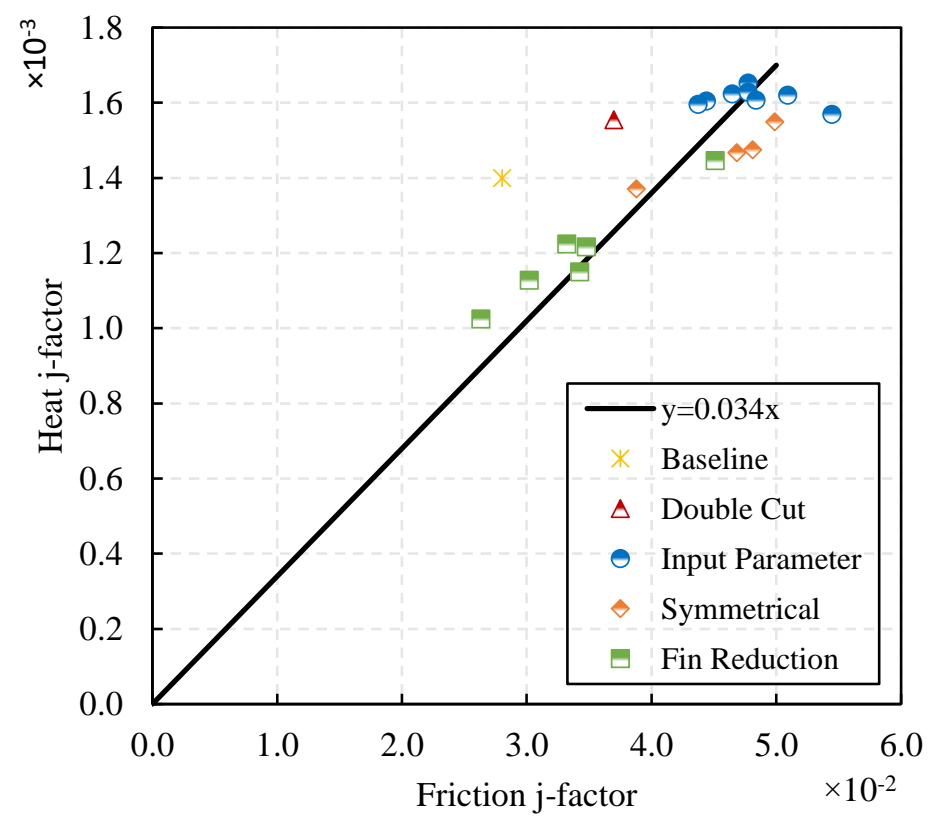

Figure 17: Correlation between heat $\mathrm{j}$-factor and friction $\mathrm{j}$-factor

To accurately compare all the designs, both the j-factors need to be divided by the mass of each design. As seen in Fig. 17, $\mathrm{j}_{\mathrm{f}}$ is now considerably higher per $\mathrm{j}_{\mathrm{H}}$. But unlike the Input Parameter from Fig. 18, 
this increase in heat transfer is much higher compared to the Baseline. However, until the mass is considered as one of the objective functions in the genetic optimisation algorithm, it cannot be known for sure if the Fin Reduction designs are actually the better design for the overall heatsink performance.

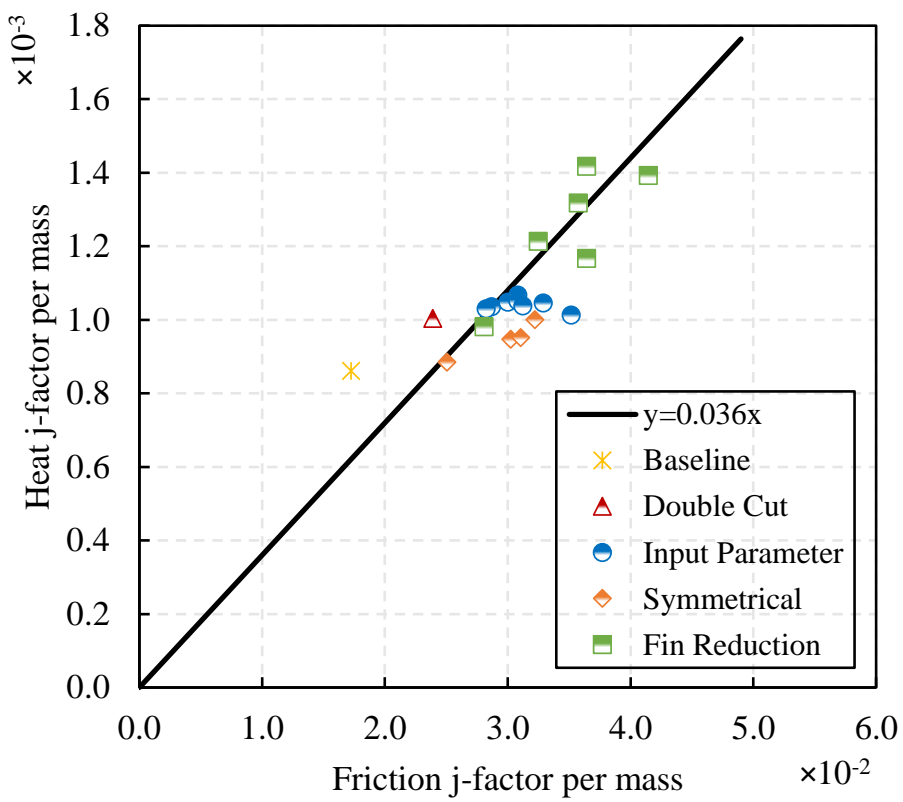

Figure 18: Correlation between heat $\mathrm{j}$-factor per unit mass and friction $\mathrm{j}$-factor per unit mass

\section{Conclusion}

This is an effort to address thermal issues in electronic components using advanced numerical optimisation techniques and propose some novel methods to enhance the efficiency of finned heatsinks. Genetic Algorithm has shown a great potential in shape optimisation and this research depicts its scope for a standard heatsink design problem, outlining potential pitfalls for their use in numerical heat transfer optimisation. The multi-objective genetic algorithm used here is able to filter out the configurations with the highest heat transfer rates and breed them until the algorithm converged on the optimal candidate. Multiple designs are simulated, showing an increase in the effectiveness of heat dissipation ranging from $11.2 \%$ to $18.1 \%$.

Four families of geometric variants with a total of twenty configurations were considered in this investigation, denoted Double Cut, Input Parameter, Symmetric and Fin Reduction. The Input Parameter designs divided the fins into groups based on the number of input parameters selected. This limited the number of fins that can rotate independently. The Symmetric optimisation operated in the same fashion as the Input Parameter. However, entire rows are grouped in order to vary symmetrically. The Fin Reduction is carried out just like the previous two, but as the name suggests, some fins are removed from the heatsink, allowing additional manoeuvrability for light-weight designs. 
The Input Parameter optimisations proved to be the most successful, especially the design IP 10, achieving an $18.1 \%$ improvement in heat transfer over the Baseline heatsink. This came at the cost of decreasing the COP by $29 \%$. However, the improvement in heat transfer is only $6.3 \%$ higher than the unaltered Double Cut design, which has a lower decrease in COP, 13\% compared to the Baseline. The improvement over the Double Cut design is therefore questionable considering the complexity of manufacture and the increase in the pressure drop.

Considering the relevance of the momentum boundary layer to the thermal boundary layers, the orientation of the Symmetric Closed design has considerably reduced the boundary layer thickness along the fins, which hindered the heat transfer by forcing the fluid to remain laminar, impeding the mixing. When a mass metric was introduced to normalise the designs and compare them fairly, the Fin Reduction designs outperformed the rest. Especially FR 646 which displayed enhancements of 65\% over the Baseline. However, until the mass is introduced as one of the objective functions in MOGA, it remains uncertain whether the Fin Reduction configurations are the optimal design.

Overall, this paper has demonstrated the upper and lower limitations of performance enhancement using evolutionary algorithms in optimising the shape of a generic plate-fin heatsink in cross-flow.

\section{Acknowledgements}

This publication has emanated from research supported in part by a research grant from Science Foundation Ireland (SFI) and is co-funded under the European Regional Development Fund under Grant Numbers 13/RC/2077 and 15/SPP/E3125. The authors likewise would like to acknowledge the support of the Irish Research Council (IRC) under grant number GOIPD/2016/216. The authors also wish to acknowledge the DJEI/DES/SFI/HEA Irish Centre for High-End Computing (ICHEC) for the provision of computational facilities and support.

\section{References}

[1]. S. V. Garimella, T. Persoons, J. A. Weibel, and V. Gektin, "Electronics Thermal management in information and communications technologies: Challenges and Future Directions," IEEE Transactions on Components, Packaging and Manufacturing Technology, 7(8), 1191-1205, 2017.

[2]. S. V. Garimella, T. Persoons, J. Weibel, and L.-T. Yeh, "Technological drivers in data centers and telecom systems: multiscale thermal, electrical, and energy management," Applied Energy, vol. 107, pp. 66-80, 2013.

[3]. G. Ledezma, and A. Bejan, "Heatsinks with sloped plate fins in natural and forced convection," Int. J. Heat Mass Transf. 39.9, pp. 1773-1783, 1996. 
[4]. D.-K. Kim, "Thermal optimization of plate-fin heatsinks with fins of variable thickness under natural convection,” Int. J. Heat Mass Transf., vol. 55, no. 4, pp. 752-761, 2012.

[5]. M. Iyengar, and A. Bar-Cohen, "Least-energy optimization of forced convection plate-fin heatsinks," IEEE Trans. on Comp. and Pack. Techs., vol. 26, 2003.

[6]. Y. Islamoglu, and C. Parmaksizoglu, "Numerical investigation of convective heat transfer and pressure drop in a corrugated heat exchanger channel," Applied Thermal Engineering 24, pp. 141-147, 2004.

[7]. I. M. Didarul, O. Kenyu, Y. Minoru, and S. Izuru, "Study on heat transfer and fluid flow characteristics with short rectangular plate fin of different pattern," Exp. Therm. Fluid Sci., vol. 31, pp. 367-379, 2007.

[8]. A. Bhattacharya, and R. Mahajan, "Metal foam and finned metal foam heatsinks for electronics cooling in buoyancy-induced convection," Journal of Electronic Packaging 128.3, pp. 259-266, 2006.

[9]. E. M. Sparrow, J. E. Niethammer, and A. Chaboki, "Heat transfer and pressure drop characteristics of arrays of rectangular modules encountered in electronic equipment," Int. J. Heat Mass Transf., vol. 25, no. 7, pp. 961-973, 1982.

[10]. J.-Y. Choi, and K.-Y. Kim, "Shape optimization of a Dimpled channel to enhance turbulent heat transfer," Numerical Heat Transfer, Part A. 48, pp. 901-915, 2005.

[11]. P. T. Lin, M. C. E. Manuel, J. Zhang, Y. Jaluria, and H. C. Gea, "Multi-objective design optimization of multiple microchannel heat transfer systems based on multiple prioritized preferences,” J. Therm. Sci. Eng. Appl., vol. 9, no. 2, pp. 021011-9, 2017.

[12]. K. Park, D.-H. Choi, and K.-S. Lee,"Numerical shape optimization for high performance of a heatsink with pin-fins," Numerical Heat Transfer, Part A. 46, pp. 229-251, 2004.

[13]. K.-S. Lee, K. Park, and D.-H. Choi, "Numerical shape optimization for high performance of a heatsink with pin-fins," Numerical Heat Transfer, Part A. 46, pp. 909-927, 2004.

[14]. I. K. Karathanassis, E. Papanicolaou, V. Belessiotis, and G. C. Bergeles, "Multiobjective design optimization of a micro heatsink for concentrating photovoltaic/thermal (CPVT) systems using a genetic algorithm," Applied Thermal Engineering 59,12, pp. 733-744 2013.

[15]. K. Horiuchi, A. Nishihara, and K. Sugimura, "Multi-objective optimization of water-cooled pinfin heatsinks,” Int. J. Heat Mass Transf., vol. 81, pp. 760-766, 2015.

[16]. C.-T. Chen, and H.-I. Chen, "Multi-objective optimization design of plate-fin heatsinks using a direction-based genetic algorithm," Journal of the Taiwan Institute of Chemical Engineers 44.2, pp. 257-265, 2013.

[17]. A. P. M. Younes, "A genetic algorithm for the shape optimization of parts subjected to thermal loading,” Numerical Heat Transfer, Part A., vol. 39, no. 5, pp. 449-470, 2001. 
[18]. Y. O. Abdelsalam, S. Alimohammad, Q. Pelletier, and T. Persoons, "A multi-objective genetic algorithm optimization of plate-fin heatsinks," IEEE $23^{\text {rd }}$ Int. Worksh. Therm. Invest. ICs and Syst., THERMINIC, Amsterdam, 2017.

[19]. M. Tye-sGingras, and L. Gosselin, "Thermal resistance minimization of a fin-and-porousmedium heatsink with evolutionary algorithms," Numer. Heat Transf. Part Appl., vol. 54, no. 4, pp. 349-366, 2008.

[20]. M. Cavazzuti, and M. A. Corticelli, "Optimization of heat exchanger enhanced surfaces through multi objective genetic algorithms," Numerical Heat Transfer, Part A., vol. 54, no. 6, pp. 603$624,2008$.

[21]. P. Teertstra, M. M. Yovanovich, and J. R. Culham, "Analytical forced convection modeling of plate fin heatsinks," J. Electron. Manuf., vol. 10, pp. 253-261, 2000.

[22]. F. P. Incopera, T. L. Bergman, A. S. Lavine, and D. P. Dewitt, "Introduction to heat transfer," Sixth Edition, pp. 68-70, 112-120, 2012.

[23]. T. H. Okiishi, B. R. Munson, D. F. Young, and W. W. Huebsch, "Fundamentals of fluid mechanics," Sixth Edition, pp. 95-123, 2009.

[24]. M. A. Boles, and Y, A. Cengel, "Thermodynamics - An Engineering Approach," Fifth Edition, pp. 287-288, 2005.

[25]. Inc ANSYS., “ANSYS Fluent User’s Guide”, pp. 257-261, 695-719, 744-776, 1418-1419, 2013.

[26]. S. Alimohammadi, N. Baudin, R. Kempers, and T. Persoons, "Multi-objective shape optimisation of Natural convection cooled plate-fin heatsinks with localised heat sources," 2nd Therm. Fluid Eng. Conf., TFEC2017, Las Vegas, NV, USA, 2017.

[27]. S. Alimohammadi, T. Persoons, D. B. Murray, M. S. Tehrani, B. Farhanieh, and J. Koehler, “A validated numerical-experimental design methodology for a movable supersonic ejector compressor for waste-heat recovery," J. Therm. Sci. Eng. Appl., vol. 6, no. 2, p. 021001, 2013.

[28]. S. Alimohammadi, D. B. Murray, and T. Persoons, "Experimental validation of a CFD methodology for transitional flow heat transfer characteristics of a steady impinging jet," J. Heat Transf. vol. 136, pp. 091703:1-9, 2014.

[29]. Malico Inc., "Heatsink", website, viewed 16 January 2016. URL: http://www.malico.com.tw/ index.php?option=com_content\&view= article $\&$ id=140:h21\&catid=52:h\& Itemid=127. 